\title{
VALUELOADING AND UNCERTAINTY IN A SECTOR-BASED DIFFERENTIATION SCHEME FOR EMISSION ALLOWANCES
}

\author{
HELEEN GROENENBERG ${ }^{1}$ and JEROEN VAN DER SLUIJS ${ }^{2}$ \\ ${ }^{1}$ Institute for Prospective Technological Studies, Edificio Expo, C/Inca Garcilaso, s/n, \\ E41092, Seville, Spain \\ Email: Heleen.Groenenberg@cec.eu.int \\ ${ }^{2}$ Copernicus Institute, Utrecht University, The Netherlands
}

\begin{abstract}
The Triptych approach is a sectoral approach for differentiation of quantitative greenhouse gas emission reduction objectives. In this study we investigate the ranges in emission reduction targets that result from differences in valueladen assumptions and uncertainties in input data and parameters. In order to assess the effect of highly valueladen assumptions on resulting objectives we used two approaches. First we performed a sensitivity analysis. Then we elaborated the approach from four ideal-typical value-orientations: the administrator, the businessman, the campaigner and the survivor. For each of these value-orientations we specified corresponding sets of assumptions of highly valueladen parameters. Within each set, we also assessed uncertainties for the remaining parameters and input data. We assessed the strength and we quantified their inexactnesses with probability distribution functions. Next, we carried out Monte Carlo simulations in each of the four value-orientations to quantify error propagation from the inexactnesses in input data and parameters. We found targets for the year 2015 for Annex I countries differed up to around 20\%-points over the four value-orientations. For developing countries differences in allowances were found up to the order of four. In addition, results are affected to a large extent by uncertainties in the other input data and parameters. Ranges in the outcome resulting from uncertainties are between 10 and 35\%-points for Annex I countries, depending on the value-orientation chosen and between 20 and 120\%-points for non-Annex I countries. However, the ranking of countries within the calculated differentiation remains roughly the same, an exception being the ranking that resulted from the businessman's perspective. Other consistent combinations of valueladen assumptions may result in objectives that are outside the range that we based on the four value-orientations. We concluded that care should be taken when assessing valueloading in calculations schemes for emissions objectives based on a limited number of value-orientations only. Our analysis clearly underlines the relevance of making explicit policy variables in schemes for the differentiation of commitments. It is necessary to reach consensus on these variables if such schemes are to support negotiations on greenhouse gas emissions allowances.
\end{abstract}

\section{Introduction}

\subsection{BACKGROUND}

One of the key issues in the debate on climate policy and equity is the question how to distribute global mitigation efforts and the costs for adaptation in an equitable manner among various parties to the United Nations Framework Convention on Climate Change. 
As for the mitigation part of the issue various approaches to differentiation of commitments have been suggested recently. These differentiation proposals mostly are based on different views of distributional fairness, for which many different categorisations can be found in the literature (see e.g. Rose, 1992; Banuri et al., 1996). In a more recent study Ringius et al. (2002) reviewed the most relevant elements for a widely accepted approach to burden differentiation in future international climate negotiations. They identified three equity principles: (1) responsibility: 'costs should be distributed in relation to a country's share of responsibility for causing the problem'; (2) capacity: 'costs should be distributed in relation to a country's ability to pay', or alternatively (see Groenenberg, 2002) to its (technical) 'ability to reduce'. According to the latter interpretation countries that can easily utilise their potentials for emission reduction would be assigned more stringent reduction targets; (3) need: 'all individuals have equal rights to pollution permits, with a minimum to secure basic human needs, including a decent standard of living'. ${ }^{1}$

Ringius et al. (2002) conclude that in order to be acceptable to a critical mass of Parties a burden differentiation scheme will have to combine two or more equity principles. In addition, no scheme that is clearly incompatible with the principle of 'need' - interpreted in terms of basic human needs - will be politically feasible. In our view a scheme that is incompatible with the principle of 'capacity' will not be feasible either, since Parties will not accept commitments that they are unable to comply with.

In recent differentiation proposals a great deal of attention has been given to viable pathways for including developing countries in a future climate regime. While the (economically) optimal solution to the climate change problem may consist of a mix of mitigation and adaptation, these proposals only consider some kind of mitigation commitment on the part of both industrialised and developing countries.

Some of these differentiation proposals focus on the type of commitments. For instance, it has been argued that for developing countries decarbonisation objectives, entailing a delinking of emissions and economic growth, might provide a good starting point (Baumert et al., 1999; Philibert, 2001a, b; Philibert and Pershing, 2001). Gupta (1999) proposed a package of options that developing countries could attempt to negotiate, such as the right of non-Annex I parties to trade excess allowances, to financial and technological transfers or to reporting commitments. In addition Gupta et al. (2001) introduced a 'graduation' method for classifying groups of countries for which different types of commitments could be negotiated based on emission and income per capita. Quantitative emission allowances apply to the most developed countries only, although an appropriate base for determining their stringency is not discussed.

Other authors focus on determining the stringency of quantitative emission allowances. An influential concept, developed by the Global Commons Institute, was the so-called 'Contraction and Convergence' approach. This approach defines emission rights on the basis of per capita emissions as converging trajectories under 
a contracting global emission ceiling. The approach has been documented more recently by Meyer (2000).

A substantially different approach to the differentiation of commitments was the Triptych approach developed in the Netherlands. This approach considered differentiation among the member states of the European Union to differentiate the EU Kyoto target (Blok et al., 1997; Phylipsen et al., 1998). New in this approach was that it was sector-based and that it took into account various national circumstances. The approach distinguished three major sectors of the economy: the energy-intensive industry, the power-producing sector and the other ('domestic') sectors. In each of these sectors specific criteria were applied to calculate partial allowances per country for each of the sectors, such as a limitation of coal use for power production, minimum requirements for the proportion of renewable energy, and minimum energy efficiency improvement rates in industry. For the domestic sectors a per capita emission allowance approach was used. The sectoral allowances were not meant to be binding in character, but merely served as an aid to calculate national allowances in a bottom-up manner.

In the FAIR model (see http://www.rivm.nl/fair/ and Berk et al., 2001) alternative climate options for international differentiation of future commitments can be explored. The model explores the 'Increasing Participation' approach, based on increasingly stringent commitments as emissions or income per capita in a country grow, the Contraction \& Convergence approach and a revised version of the Triptych approach. The stringency of the commitments is chosen such that the sum of global emissions does not exceed a predefined emission ceiling.

Blanchard et al. (2001) came up with their 'Soft Landing' approach. This approach entails a progressive stabilisation of emissions in countries without quantitative commitments under the Kyoto Protocol. The timing and level of commitment would depend on per capita emissions and per capita income, as well as on population growth. This approach also links total emissions to targets for global climate protection.

Inspired by the Triptych approach and the concept of converging per capita emissions Sijm et al. (2001) introduced the Multi-Sector Convergence approach to calculate quantitative emission allowances in a sector-based scheme. The method entails a convergence of per capita emissions in each of seven economic sectors. A per capita emission standard in each of the sectors follows from the present global per capita emissions in that sector and an assumed mitigation policy effort. Although economic structure is well considered, the approach has a conceptual difficulty. Apparently, it contains no valid justification for ultimately equal per capita emissions in all sectors. For some sectors such as households or transport, convergence of per capita emissions may hold, after some corrections for climatic differences or differences in transportation distances. However, international specialisation in the manufacturing industry for instance or an uneven distribution of natural resources may for a certain country lead to permanently higher per capita emissions in industry or the power-producing sector. Admittedly Sijm et al. (2001) 
introduced correction factors to make up for such international differences, but this seems a laborious way to smooth differences that cannot and need not be removed.

Müller (2001) contributed to the differentiation debate by stressing the morally ambiguous character of the differentiation issue, as well as the dynamic nature of any moral context. Not only do perceptions of equity diverge among negotiating Parties, they may also change over time. He advocates effective procedures to realise a fair differentiation of commitments and to this end has introduced a Global Compromise Scenario. This entails a scoring procedure which weights preferences for different equity principles among negotiating Parties.

We found that in the literature on the stringency of emission objectives emphasis is either on a global emission ceiling, on some notion of equity, on the specific needs of developing countries or on cost-effectiveness. A partial exception may be the introduction of world-wide convergence trajectories for per capita emissions in all emitting sectors (Sijm et al., 2001). However, such an approach lacks a fundamental argumentation and several correction factors are needed to make up for differences in national circumstances.

We wish to put forward an alternative allocation scheme that reflects production growth, economic structure and technological development. Since the Triptych approach has been useful for differentiating the EU Kyoto target among Member States, this approach has been taken as a starting point for the investigation.

We think it is a viable approach since it incorporates both the equity principle of capacity and the principle of need. With its focus on technology and national circumstances it proved a useful decision support tool within the European Union and it may well be of use in the global context. A preliminary exploration of how this method might work out if scaled up from a European to a global scale has been made by Groenenberg et al. (2001). This paper constitutes a further exploration of the Triptych approach. Insights gained from the present study have been used to make the original approach more suited for the global context (Groenenberg, 2002).

Note that while mitigation commitments can take many forms, the Triptych approach focuses on quantitative emission limitation objectives only. Alternative types of commitments such as policies and measures for e.g. carbon taxes, voluntary agreements with national businesses, financial transfers to affected countries or technology transfer agreements are not considered.

\subsection{VALUELOADING AND UNCERTAINTY}

A central point in this article will be that the quantitative specification of an approach to the differentiation of commitments depends on the value-orientation of the user(s) of the approach. Within the European Union the specification of the Triptych approach was done in an interactive manner. The approach was presented at an informal workshop to the negotiating Member States, in which four variants 
were outlined (Blok et al., 1997; Ringius, 1999). The four variants differed with respect to the assumed rate of emission reduction in the domestic sectors, energy efficiency improvement in the energy-intensive industry and the extent to which national climate targets were taken into account. Thus, four sets of quantitative emission allowances were presented on which policy makers could comment. The calculated allowances varied as a consequence of different choices for parameters as the rate of emission reduction in the domestic sectors or the assumed rate of energy efficiency improvement in the energy-intensive industry may vary. They depend on how great value somebody attaches to early action regarding the climate problem, and on how economic risks associated with a speedy mitigation strategy are perceived. Thus, although not explicitly stated there, different opinions and values may be reflected in various parameter settings in the Triptych approach. This is what we call valueloading.

Apart from this issue of valueloading it should be acknowledged that all of the parameters and data in the approach are surrounded by uncertainties to a smaller or larger degree. These uncertainties do not so much depend on the perspective of the user or analyist, but instead result from errors and limitations in methods and measurements. Emissions or population estimates are obvious examples of this. Funtowicz and Ravetz (1990) distinguished three types of uncertainty. Inexactness refers to the fact that a variable's actual value may be anywhere in a range and can deviate from the value that is being used. Unreliability refers to the level of confidence, quality soundness, scientific status etc. of the knowledge. Its inverse may be referred to as strength. Ignorance refers to incomplete understanding.

\subsection{OBJECTIVE AND RESEARCH QUESTIONS}

We want to look in more detail in the issues of valueloading and uncertainty in the Triptych approach for two reasons. First, we want to investigate to what extent the outcome of Triptych calculations is sensitive to different assumptions and uncertainties in its parameters and input data. As the stringency of emission reduction targets bears far reaching consequences for national climate policies, a clear understanding of the factors affecting the outcome of differentiation calculations is important. Second, an increased insight into the relative importance of sources of uncertainty in the outcome of Triptych calculations may help to focus future research on those parameters and input data identified as important.

For our analysis we will use the explorative assessment of the Triptych approach on a global scale that has been introduced by Groenenberg et al. (2001), which comprises fossil fuel related $\mathrm{CO}_{2}$ only. Our study will comprise valueloading on the one hand and uncertainty on the other. We will leave out ignorance as a source of uncertainty as it is inherently impossible to investigate this type of uncertainty for an insider. Neither will we address the structural uncertainties and valueloading incorporated in the algorithms chosen. Although the algorithms reflect what notion 
of equity is aimed at and determine to a large extent the outcome, it is difficult to systematically test how alterations here would work out. Since the algorithms are inherent to the set of differentiation rules assessed, altering these would disrupt the approach or model as such. A better way would be to compare outcomes from the Triptych approach to differentiation schemes using other basic interpretations of fairness. Such a comparison is beyond the scope of this paper. Therefore, we keep the algorithms fixed and focus on the uncertainties in the input data and parameters and valueloading that comes with the choice of some parameter values. We, therefore, formulate our research question as follows:

What are the ranges in emission reduction targets that result from valueloading and uncertainty in input data and parameters and how does it affect the ranking of countries according to resulting commitments?

This question may be split into the following partial questions:

1. How may each of the valueloaded assumptions affect the outcome of Triptych calculations?

2. How can the spectrum of value-orientations regarding adequate climate change mitigation strategies be incorporated in Triptych calculations?

3. How is the ranking of countries according to resulting commitments affected by valueloading in the parameters?

4. What are plausible inexactness ranges in input data and parameters?

5. What is the unreliability of input data and parameters?

6. How large are the ranges of emission reduction targets that result from inexactnesses in the parameter values and input data within each of the valueorientations distinguished?

7. Which uncertain parameters and input data contribute most to the variance in the outcome?

In this study we will use 2015 as an exemplary target year to establish allowances using the Triptych calculations, which will possibly be the middle year of the second budget period for which new allowances are still to be negotiated. We confined the analysis to 10 countries from various coalitions in the international climate negotiations (Table I). Together they are responsible for over $70 \%$ of global combustion related $\mathrm{CO}_{2}$ emissions (in 1996: IEA, 1997a). In the following we will first briefly describe the Triptych approach to differentiation of commitments. Then we will address the problem of valueloading. To this end we will present the initial results for a selection of ten countries, including the European Union as a whole, and perform a number of sensitivity analyses for a number of highly valueladen assumptions. Next, we will explain our objections against this method of dealing with valueloading and we will come up with an alternative framework to deal with the issue of valueloading more effectively. In this framework we will distinguish four different value-orientations: the administrator, the businessman, the 
TABLE I

Countries included in the analysis and $1990 \mathrm{CO}_{2}$ emissions from fuel combustion (IEA, 1997a, UN, 1998)

\begin{tabular}{lll}
\hline & $\begin{array}{l}\text { Total } \mathrm{CO}_{2} \\
\text { emissions }(\mathrm{Gt})\end{array}$ & $\begin{array}{l}\text { Total } \mathrm{CO}_{2} \text { emissions } \\
\text { per capita }(\mathrm{t} / \mathrm{c})\end{array}$ \\
\hline Australia & 0.27 & 16 \\
Brazil & 0.22 & 1.5 \\
China & 2.4 & 2.1 \\
European Union & 3.2 & 8.9 \\
India & 0.60 & 0.7 \\
Japan & 1.1 & 8.6 \\
Norway & 0.023 & 5.5 \\
Poland & 0.35 & 9.2 \\
Russia & 1.9 & 13 \\
\hline
\end{tabular}

campaigner and the survivor. For each of the value-orientations we specify bundled assumptions of highly valueladen parameters. We adopted these ideal typical valueorientations for their analytical convenience and familiarity only; we do not intend to describe the political negotiation process with them. For the remaining parameters and input data we use a different and complementary framework to assess their uncertainties. We assessed the strength and we quantified their inexactnesses with probability distribution functions. Next, we carried out Monte Carlo simulations for each of the four value-orientations separately, to assess the propagation of errors in the resulting emission reduction objectives. Thus, we come up with four ranges of emission reduction objectives for each of the 10 countries included in this study. We end with a discussion and conclusions.

\section{The Triptych Approach}

The Triptych approach (Phylipsen et al., 1998, Groenenberg et al., 2001) is a sectoral approach distinguishing three categories of emissions, corresponding to three groups of economic sectors: the energy-intensive industry, the power-producing sector and the domestic sectors. Accounting for varying national circumstances different criteria are used for each of the three categories to calculate sectoral allowances. The allowances for each sector add up to proposed national allowances for the target year under consideration. The Triptych approach offers a sectoral analysis only as a transparent tool to determine national allowances. It does not establish sectoral commitments, agreed on either at the national level or at the level of economic sectors, as this would hamper countries in their flexibility to pursue cost-effective emissions reduction strategies. We will now briefly describe each of 
the three sectors. Note that Groenenberg (2002) specified the various input data and parameters in each of the sectors. The algorithms for each of the sectors have been given in Appendix I.

The internationally oriented energy-intensive industry has relatively high $\mathrm{CO}_{2}$ emissions per monetary unit of production. The rationale for distinguishing this sector separately is that countries that rely to a large extent on this sector have higher $\mathrm{CO}_{2}$ emissions than countries that are more dependent on services, light industry or agriculture. Disregarding the contribution of this sector may therefore disadvantage the competitiveness of industries in these countries. Furthermore, the international character of this sector means that countries lacking sizeable energyintensive industries import energy-intensive commodities from other countries and thus profit from other countries' emissions in this sector. In order to establish national allowances growth assumptions are made for the physical output of some major industrial subsectors. In addition a criterion for energy efficiency improvement and decarbonisation is applied.

The power-producing sector has been distinguished because specific $\mathrm{CO}_{2}$ emissions (i.e. expressed per unit of power produced) from power production vary to a large extent, due to large differences in the share of nuclear power and renewables and in the fuel mix in fossil-fuel-fired power plants. The potential for cutting $\mathrm{CO}_{2}$ emissions from this sector differs accordingly. Therefore, fuel mix in power generation is an important national circumstance to account for in a differentiation of commitments. In order to establish national allowances, specific criteria on the composition of the fuel mix in the target year may be formulated, for instance on the reduction of fossil fuel based capacity or the share of renewables in electricity production.

The domestic sectors comprise all remaining sectors. Apart from the residential sector (households), also the commercial sector, transportation, light industry and agriculture are included in this category. Emissions in these sectors are assumed to be primarily correlated with population size, as they are determined to a substantial extent by the number of people that live in dwellings, have a workplace, transport themselves, etc. Therefore, a per capita allowance is defined for emissions in the domestic sectors. As a reduction criterion it is assumed that per capita emission levels for various countries converge to equal per capita allowances for all global citizens in some future year in the coming century.

\section{Valueloading}

\subsection{SENSITIVITY ANALYSES FOR HIGHLY VALUELADEN PARAMETERS}

In the following we will perform a number of sensitivity analyses for the initial calculations by Groenenberg et al. (2001). To this end we will single out a number of parameters in the Triptych approach that take a special position. These parameters 
are more so than the others, to a large extent valueladen. They include (1) assumptions on the fuel mix in power generation in the target year, (2) the year in which per capita $\mathrm{CO}_{2}$ emissions in the domestic sectors are supposed to converge, and (3) the level at which these emissions converge. The various stakeholders in the international climate debate hold diverging views on the way hurdles to the transition to a carbon low economy should be overcome. As a consequence, the value of these parameters may be chosen differently depending on the value-orientations of the stakeholder and will be difficult to underpin with for instance measurements or historic trends. Other parameters, such as rates for economic growth or growth of physical production in the energy-intensive industry may be affected by the valueorientation of the user of the approach as well. However, some measure exists to establish these parameters as they may be compared to or to a certain extent derived from historic data. Therefore, we do not consider valueloading in these parameters as a dominant source of uncertainty and confine ourselves to what we will call highly valueladen parameters.

In the following we will present the original Triptych calculations (the base case) by Groenenberg et al. (2001) for a set of ten countries. These will be listed alongside with the results of sensitivity analyses for (1) fuel mix in power generation; (2) the year in which per capita emissions in the domestic sectors are assumed to converge; (3) the level at which these converge.

Four hypothetical fuel mixes for power generation are presented in Table II. Table III shows how sensitive emission limitation objectives, total $\mathrm{CO}_{2}$ emissions and total $\mathrm{CO}_{2}$ emissions per capita are to alternative fuel mixes. Resulting targets may deviate from base case targets several tens of percents.

We also assessed how objectives would alter if the convergence level for domestic emissions ( $3.4 \mathrm{t} / \mathrm{c}$ ) would be attained later in the future (i.e. 2050 or 2100). Table IV shows the results. Obviously this resulted in respectively much looser and more stringent objectives for all countries.

Table $\mathrm{V}$ presents the targets that we calculated using an alternative level for per capita emissions in the domestic sectors in 2030. We increased and

TABLE II

Composition of the fuel mix in power generation in four sets of Triptych calculations

\begin{tabular}{lllll}
\hline & Base case & $\begin{array}{l}\text { Fuel mix } \\
\text { constant }\end{array}$ & $\begin{array}{l}\text { Accent on } \\
\text { renewables }\end{array}$ & $\begin{array}{l}\text { Differentiated } \\
\text { rich and poor }\end{array}$ \\
\hline Coal & $-30 \%$ & & $-50 \%$ & Rest \\
Oil & $-30 \%$ & Constant & $-50 \%$ & $-10 \%$ \\
Gas & Rest & Share & Constant & $+100 \%$ \\
Combined heat and power & $+15 \%$ & & $+20 \%$ & $+0 \%$ \\
Nuclear & Constant share & $-100 \%$ & $+100 \%$ \\
Renewables & $\begin{array}{l}\text { 8\% share on top } \\
\text { of 1990 output }\end{array}$ & Rest & $+1 \%$ \\
\hline
\end{tabular}




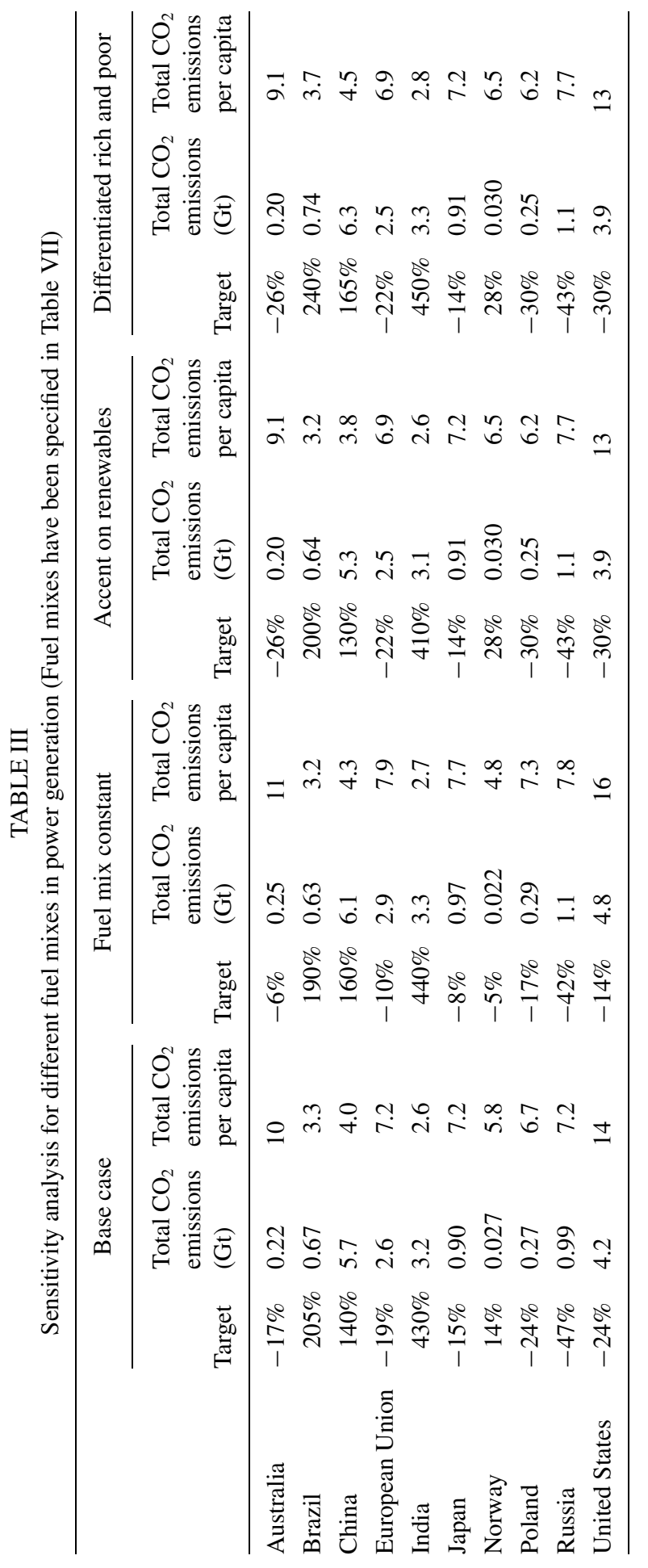




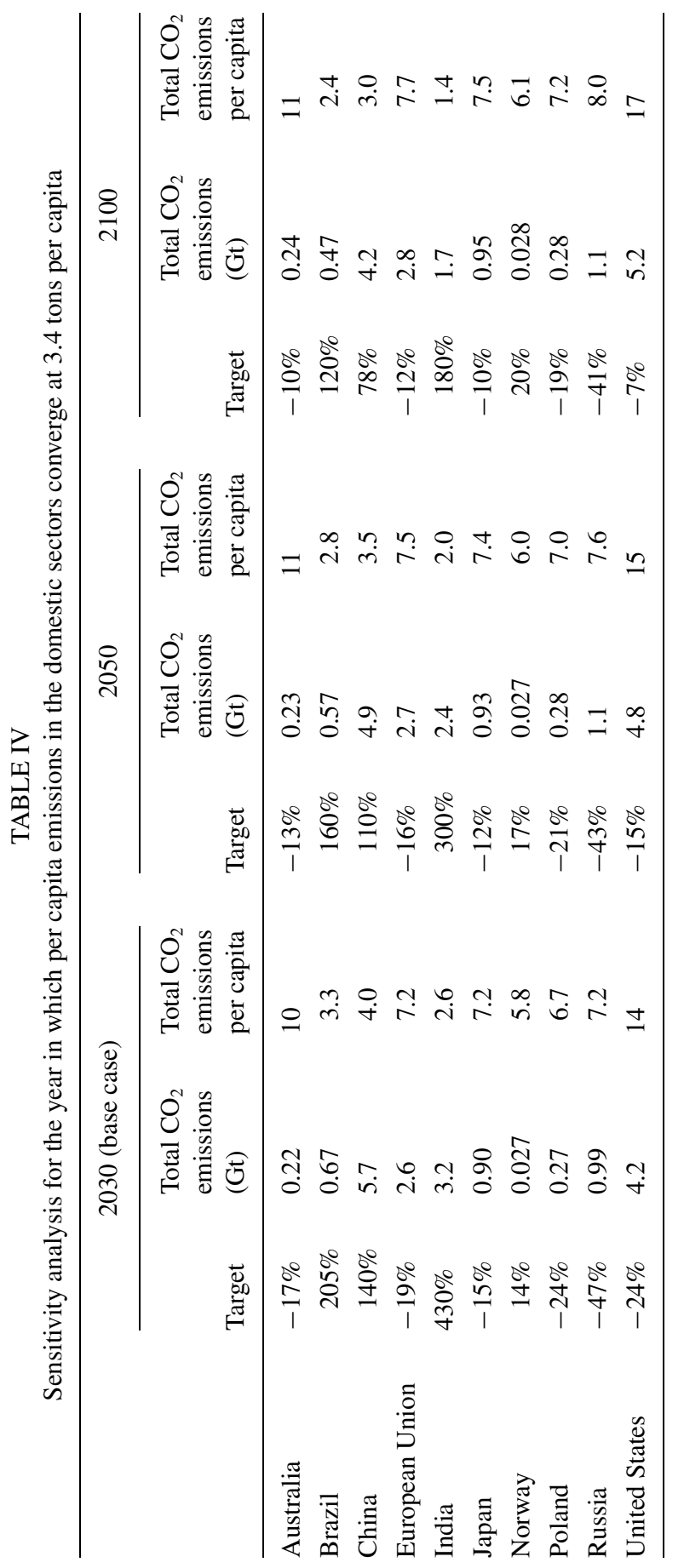




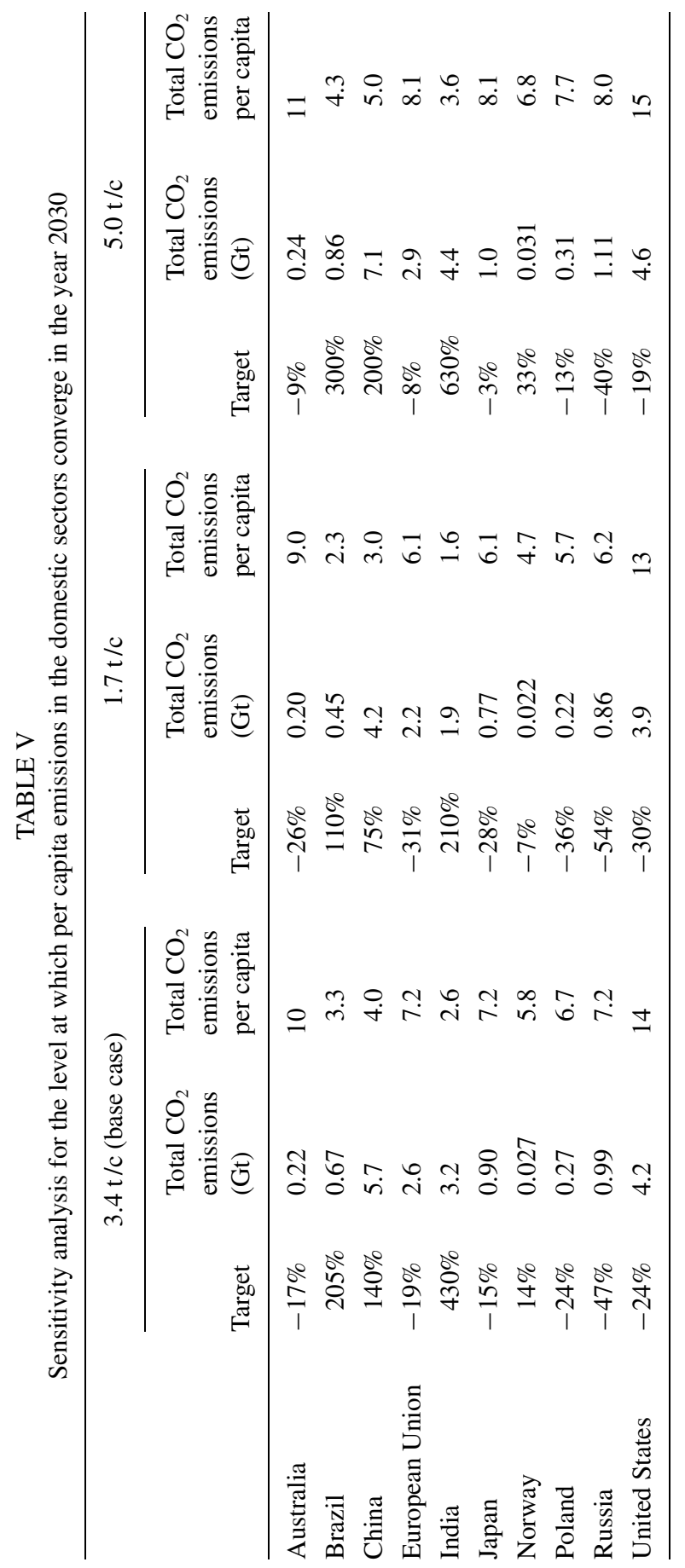


decreased the base case level (3.4 ton/capita) by 50\%. The effect of looser and more stringent objectives was larger than the effect of a later convergence year.

Finally, we performed a series of sensitivity analyses with cross-combinations for all highly valueloaded parameters. This resulted in minimum and maximum values for three policy variables: targets, total $\mathrm{CO}_{2}$ emissions and total $\mathrm{CO}_{2}$ emissions per capita (Table VI). Obviously the range for each of the three policy variables is large.

These sensitivity analyses give some insight in the degree to which important policy variables (i.e. targets, total emissions and total emissions per capita) may vary as a consequence of alternative valueladen assumptions. Nevertheless, there are a number of drawbacks to assessing the effect of valueloading on the outcome in this manner.

First, the total range in emission limitation targets is very large, as we just demonstrated. This large range results from cross-combining all valueloaded parameters. The realistic content of some of these cross-combinations may be questioned and may have led to minimum and maximum values for the policy variables that probably nobody will be interested in. For instance, convergence of domestic emissions at $1.7 \mathrm{t} / \mathrm{c}$ in the year 2030 and a fuel mix with an accent on renewables will result in very stringent and possibly infeasible emission limitations, for all countries, in particular in the industrialised world.

Second, the sensitivity analyses above do not take into account that valueloaded parameters in the approach are mutually linked and should be consistent. It is unlikely that anybody would choose e.g. to keep fuel mix in power generation unaltered, while reducing emissions in the domestic sectors sharply by choosing a low convergence level in a nearby year.

Third, it may be expected that the results of a sensitivity analysis for the remaining data and parameters in the approach (e.g. data on emissions and population or a feasible efficiency improvement in heavy industry) depend on the highly valueloaded parameters that we just tested. For instance, the more domestic emissions are assumed to alter, following assumptions on year and level of convergence of per capita emissions in this sector, the less important will be uncertainties in population statistics for the outcome of the calculations. Therefore, we wish to find a way to assess these uncertainties in a way that takes into account this influence of valueloaded parameters.

For these reasons we wish to use an alternative framework to address the issue of valueloading in the Triptych approach, which we will introduce hereafter.

\subsection{CULTURAL THEORY}

In the following we will explore how the Triptych approach may work out starting from different value-orientations of the climate change issue that may be preferred 


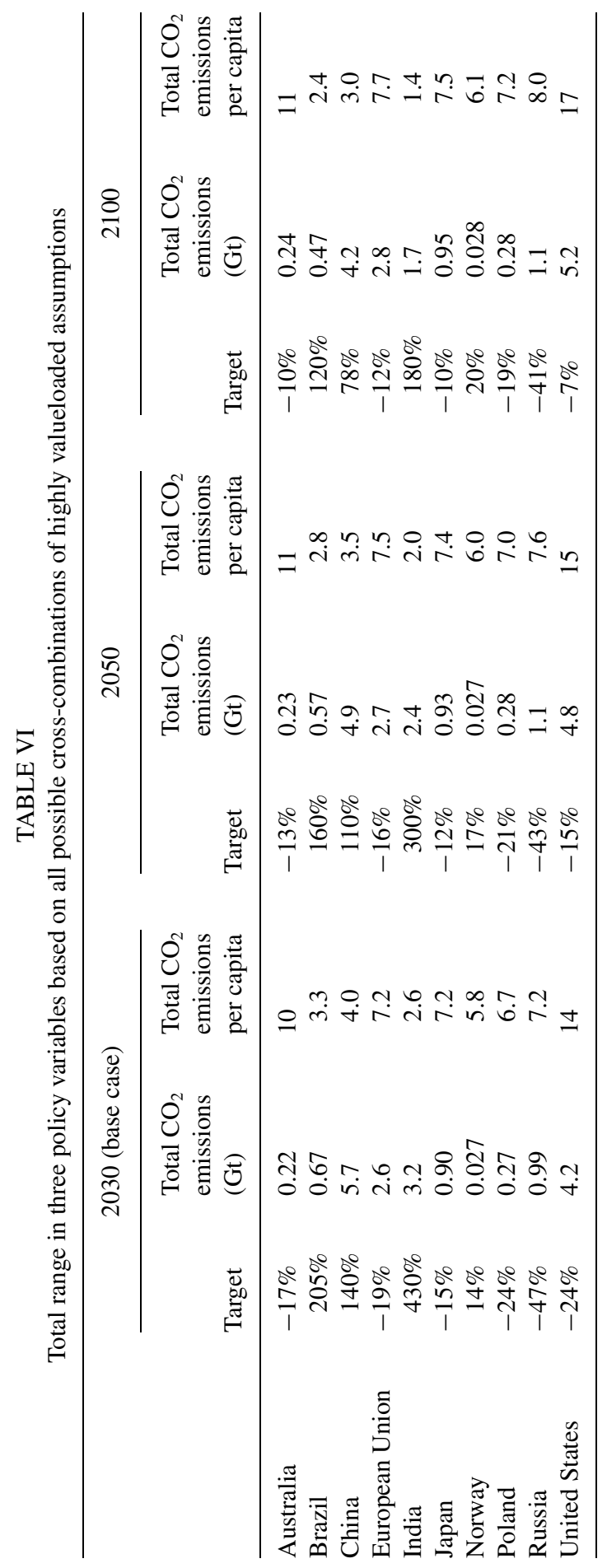


by different users. To this end we will use a variant of cultural theory as a framework to structure the analysis of the role different value-orientations.

Cultural theory was developed by Douglas (1982) who introduced grid/group analysis to unravel social variation among individuals. Variation was reduced to a few ideal types, characterised by two dimensions. The first dimension is the degree to which an individual feels committed to decisions or preferences of the group he is in. He may prefer to operate on his own, in an individualised way, or rather seek connection to the group he is part of and thus operate in a collectivised manner. The second dimension concerns the extent of regulation within a group that an individual feels happy with. He may on the one extreme choose to make his choices independently from his social surroundings or on the other extreme not have any problems with restrictions that the group poses on his choices. Douglas (1982) refers to the latter dimension as grid control. In the interpretation by Schwarz and Thompson (1990) grid may run from maximum freedom in an unregulated life in which the individual may prescribe his own rules, to maximum regulation, as for instance in a military regiment with its prescribed behaviour and rigid timetabling.

Considering the grid and the group dimensions thus four ideal types of individuals may be distinguished each with its own rationality: the hierarchist, the egalitarian, the individualist and the fatalist (see Figure 1; Schwarz and Thompson, 1990; Thompson et al., 1990).

Cultural theory has been applied in multidisciplinary studies of global climate change (see e.g. Rotmans and de Vries, 1997). However, a number of critiques of cultural theory have been published as well. Several critiques have been summarized by Baer (1998), while Ravetz (2001) gives a number of additional objections.

One of the problems, indicated by Ravetz (2001), is that the fatalist does not fit as smoothly into the framework as do the other three ideal types. Fatalists may be characterized as the marginal members of society who do not feel to have a place

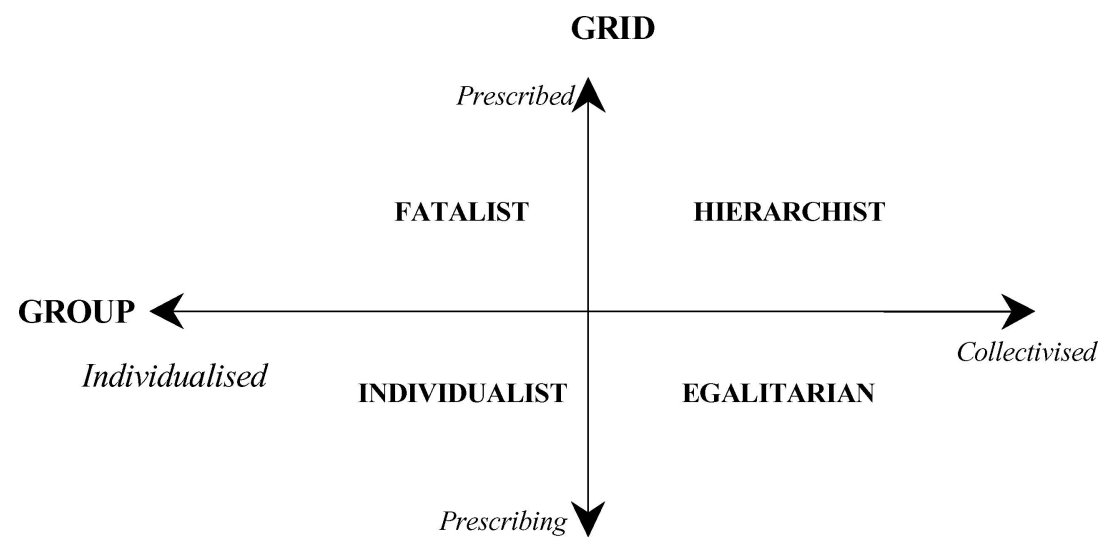

Figure 1. Cultural theory: Two dimensions of social variation and four resulting rationalities (Schwarz and Thompson, 1990). 
in society. Therefore, the degree of grid control in this society is irrelevant to the fatalist, and an obvious argument for classifying fatalists as preferring a high degree of grid control is lacking.

Ravetz (2001) notices a second problem in cultural theory. Although the theory aims to describe different types of individuals as identified through various social settings, in his view this mixture of social environments and resulting individualities may confuse the reader: does cultural theory address social variations among individuals, or does it rather describe the behaviour of groups?

A third problem is that no agreement exists on the causal relationship between 'social relations' on the one hand and 'values and beliefs' (or worldviews) on the other (Boholm, 1996; in Baer, 1998). Some argue that social relations determine worldviews, while others prefer to stick to the explanation that social relations and worldviews interact and reinforce each other.

Fourth, Boholm (1996) points out that cultural theory does not give a satisfactory explanation of the possibility each individual has to change worldviews. Individuals tend to look around for alternative and/or better opinions or lifestyles. This requires that he or she has a rational perspective that is outside his or her personal biases. Such rationality does not fit the theory's presumption that people cannot step out of their own perspectives. Trisoglio (1995) and Van der Sluijs et al. (2002) also commented on the static character of cultural theory.

Fifth, the statistical underpinning of the theory has been criticised. Sjöberg (1997, in Baer, 1998) looked at eight different published works that use cultural theory to explain environmental risk perception. He found that cultural biases contribute very little to the explanation of risk perception. Boyle and Coughline (1994) conclude that worldviews can be predicted from grid-group combinations, but found that linkages between grid-group and worldview are not always what cultural theory predicts. Therefore, its explanatory and predictive power of the theory is limited.

Sixth, various authors criticised the simplicity of cultural theory. Trisoglio (1995) designated cultural theory as an oversimplification of reality. In his view it is too static and holds undue universal claims, while not taking account of complex systems of myths of nature. Van der Sluijs et al. (2002) criticised the use of cultural theory in integrated assessment for the same reason. It would restrict the problem structuring to static problem definitions in terms of pre-defined theoretical (ideal-typical) categories. This hampers the confrontation and integration of differing perspectives and differing value positions into new ways of looking at the problem.

A final and important criticism of cultural theory is from Baer (1998). He states that the theory reflects a type of cultural relativism, according to which all scientific and ethical argument would become impossible. People would be locked into their own values and beliefs and would not be able to draw from common ethics or standards to resolve common (environmental) problems. Baer argues that people with different perspectives in reality would share enough common values for the environment and considers a constructive dialogue on solutions possible. 


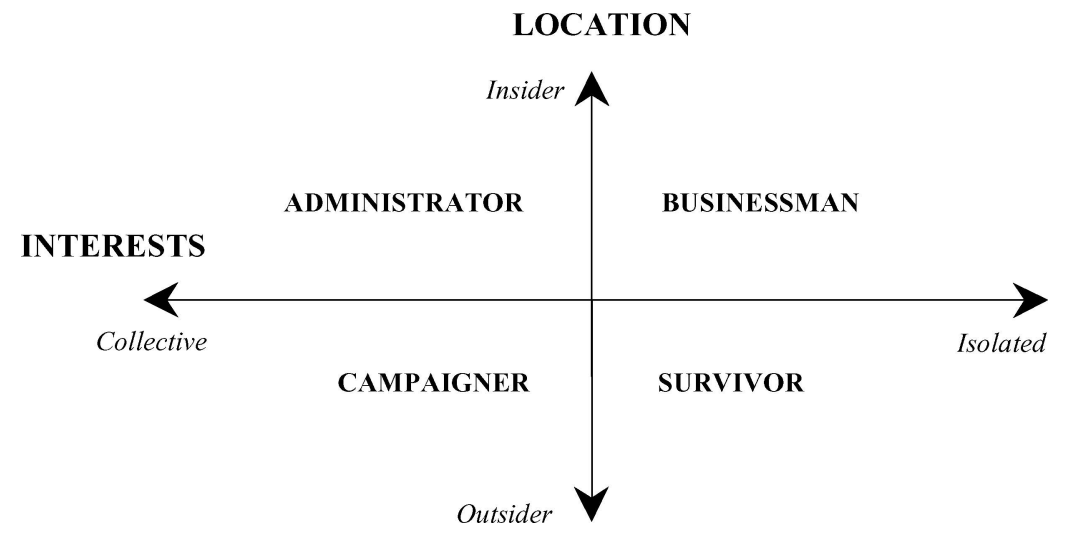

Figure 2. Cultural theory with modified axes and actors (Ravetz, 2001).

In this study we will apply a modification of cultural theory, put forward by Ravetz (2001). In this modified cultural theory axes and ideal types are adapted.

The ideal types of individuals Ravetz (2001) distinguishes are the Administrator, the Businessman, the Campaigner and the Survivor (ABCS, Figure 2). Two axes describe these ideal types. The vertical axis describes a person's relation to the prevailing social order, in particular the extent to which he identifies himself with the prevailing preferences and values. This axis more or less corresponds to the group axis in cultural theory as described by Schwarz and Thompson (1990). The horizontal axis describes the style of action, which may be anywhere between 'isolated' and 'collective'. For our purpose we will interpret this dimension as the interests that are being looked after primarily, which may be own interests or rather common interests. It can be argued that a campaigner and an administrator will be more concerned with climate change than the average businessman or someone for whom surviving is the number one priority.

In this modified version some of the difficulties perceived in traditional cultural theory are overcome. For instance the problematic ideal type of the fatalist has been left out in this modified version. Furthermore, this version starts with more real-life typifications than the abstract ones in traditional cultural theory. Therefore, it seems to emphasize social variation among individuals rather than among groups. Note, however, that a number of the objections to cultural theory that we summarized above, still apply to this modified version. It does not shed light on the interaction between social relations and worldviews. Neither does it provide for an explanation why or how individuals would change their perspective. Furthermore, just as traditional cultural theory, this modified version has not been statistically underpinned and it may be designated an oversimplification of reality. Finally, Baer's (1990) major objection against cultural theory also holds for this modified version of cultural theory: it may hamper scientific and ethical arguments on solutions to environmental problems. 
Notwithstanding the controversies surrounding cultural theory, we chose to use Ravetz'(2001) modified version thereof because it provides a convenient and resource extensive analytical framework to systematically explore issues of valueloading. We do not pretend to cover global variation in value-orientations fully by these stereotypes. They merely serve to explore indicatively how the Triptych approach may lead to different results, depending on a user's value-orientation. We are fully aware of the limitations of cultural theory, even in the improved version we adopt here; and our use of it should not be taken to imply our agreement with claims on the universal nature of cultural theory or with the political implications that have sometimes been drawn from it. We do not wish to apply it to predict the outcome of climate negotiations or the public's views on solving the climate change problem. We use the typology only for analytical purposes recognising explicitly that people have their own conceptual frameworks, which have consequences for their day-to-day decisions and behaviour as well as for the results of scientific research and modelling work. This does not need to imply that an individual could not reflect on his own preferences. On the contrary, an awareness of own and other's personal biases might well further reflection thereupon. Neither does cultural theory necessarily contradict the fact that apart from personal values and beliefs some common ethics may exist as well. We think that the application of cultural theory in this study may help to increase awareness of personal biases in the application of the Triptych approach. In this first study of the problem, we felt that with all its defects, this framework (as modified here) has the merits of being analytically convenient and uses types that are more familiar to readers than the ones from the original cultural theory. We realise, however, that our definition of four value-orientations is cursed with our own personal bias. The ideal-types may be defined in other ways as well. A more sophisticated and realistic framework would entail elicitation of stakeholder values. Van der Sluijs and Kloprogge (2001) reviewed a number of alternative approaches to include stakeholder perspectives in assessment studies. They concluded that ideal-typical approaches are suitable for exploratory studies, whereas studies that are directly linked to decision making processes require a bottom-up approach, actively involving stakeholders. Both Van der Sluijs et al. (2002) and Stirling and Mayer (2001) demonstrated innovative bottom-up approaches to do so. Elicitation of stakeholders value-orientations, however, would have required much greater resources costs for the research, which would have been difficult to justify for this exploratory project. Having said this, we will now briefly characterize the four ideal types that we used in our study.

To start with, the administrator could for instance be a government official from some northern OECD country. He takes the climate issue seriously and aims to strengthen early action, which has already been initiated. At the same time he faces the reality of inertia in realising real GHG emission reductions and the fact that domestic stakeholders in various sectors of the economy will have to live up to reduction targets. The businessman we put forward here is an average businessman in an industrialised country. His number one priority is maximising the profits 
of his own company. He has heard of the climate issue, but trusts that society will evolve to a carbon-low economy in time and that the market will provide adequate incentives for this. The campaigner is critical about traditional social structures and preferences. He works for some environmental non-governmental organisation and is extremely worried about the rate at which the global climate may continue to change. He beats the drum continuously for immediate and comprehensive action, in particular from the industrialised world, demanding that all stops be pulled out to turn the tide. Finally, the survivor is a representative of a developing country whose chief concern is today. He feels the victim of the climatic consequences of early Annex I industrialisation and often objects against the prevalence of typical northern values including globalisation and the valuation of profit maximisation. He holds the view that solutions for the climate problem should come from the industrialised world, and demands to be enabled to fulfil his own needs.

\subsection{QUANTIFICATION OF VALUE-ORIENTATIONS}

For our elaboration of the four value-orientations we will single out a number of highly valueloaded parameters in the Triptych calculation scheme. These are the same as the parameters that we used in Section 2 to perform some sensitivity analyses. However, instead of testing the effects of alternative assumptions for each of these parameters separately, we will now bundle them. For each of the four value-orientations just presented we will make a combination of fuel mix in power generation, year and level for the convergence of per capita emissions in the domestic sectors (Table VII). The fuel mixes are the same as the ones in the sensitivity analysis (Section 3.1). With regard to the year and level of convergence of per capita emissions in the domestic sectors we draw from two of the four (non-intervention) storylines presented by the Intergovernmental Panel on Climate Change (Nakićenović et al., 2000), namely, the A1 and the B1 storylines. Both describe converging worlds, the former with an emphasis on economic growth, the latter stressing environmental values. We chose these storylines as they seem to match most the philosophy behind the Triptych approach, which encompasses a converging world, at least as far as emissions in the domestic sectors are concerned. While six modelling teams around the world implemented the various storylines, we derived the level of per capita emissions in the domestic sectors in various years in the A1 and the B1 storylines from the IMAGE-team's implementation (2001). This is because contrary to the elaborations by the other modelling teams this is the only implementation distinguishing the domestic sectors as defined in the Triptych approach separately. In the following we will explain our specification of the parameters in each of the value-orientations.

To start with the administrator we propose here adheres to stabilisation of atmospheric greenhouse gas concentration at a rate that will not harm the economy. In 
TABLE VII

Illustrative preferences for a number of highly valueladen parameters in the Triptych approach from four value-orientations

\begin{tabular}{|c|c|c|c|c|c|}
\hline & \multirow[b]{2}{*}{ Administrator } & \multirow[b]{2}{*}{ Businessman } & \multirow[b]{2}{*}{ Campaigner } & \multicolumn{2}{|c|}{ Survivor } \\
\hline & & & & Annex I & Non-annex I \\
\hline \multicolumn{6}{|c|}{2015 fuel mix in power generation (output based) } \\
\hline Coal & $-30 \%$ & & $-50 \%$ & $-50 \%$ & Rest \\
\hline Oil & $-30 \%$ & Constant & $-50 \%$ & $-50 \%$ & $-10 \%$ \\
\hline Gas & Rest & Share & Constant & Constant & $+100 \%$ \\
\hline $\begin{array}{l}\text { Combined heat } \\
\text { and power }\end{array}$ & $+15 \%$ & & $+20 \%$ & $+20 \%$ & $+0 \%$ \\
\hline Nuclear & Constant share & & $-100 \%$ & $-100 \%$ & $+100 \%$ \\
\hline Renewables & $\begin{array}{l}8 \% \text { share on top } \\
\text { of } 1990 \text { output }\end{array}$ & & Rest & Rest & $+1 \%$ \\
\hline \multicolumn{6}{|c|}{ Convergence of per capita emissions in the domestic sectors } \\
\hline Level (t $\mathrm{CO}_{2}$ per capita) & 5.0 & 2.1 & 1.7 & & 3.8 \\
\hline Year & 2030 & 2100 & 2100 & & 2050 \\
\hline $\begin{array}{l}\text { Based on storyline } \\
\text { (Nakićenović } \\
\text { et al., 2000) }\end{array}$ & B1 & $\mathrm{A} 1$ & B1 & & B1 \\
\hline
\end{tabular}

such a value-orientation somewhat stringent but feasible criteria regarding fuel mix in power generation fit well. We will maintain the criteria that have been used in the preliminary assessment by Groenenberg et al. (2001; the base case) who based them on the criteria used for the internal EU burden sharing of the Kyoto target (Phylipsen et al., 1998).

Since in our administrator's value-orientation the mitigation of climate change is a highly relevant issue we will derive the administrator's preference for level and timing of per capita emissions in the domestic sectors from the B1 scenario, which encompasses a convergent world with a high environmental awareness. In this scenario global greenhouse gas emissions peak halfway this century and decline afterwards. As administrators in general have a rather short time horizon for their policies, we set the administrators' preference for a year of convergence at 2030. The IMAGE team's interpretation (2001) of the B1 storyline implies an average level of domestic per capita emissions in the OECD of 5.0 ton $\mathrm{CO}_{2}$ by then, which we will thus use as level of convergence of domestic per capita emissions. Further, reductions in the remainder of the century may then follow the B1-trajectory for all countries simultaneously.

Second, our businessman adheres to a more flexible approach to limit greenhouse gas emission reductions than the administrator does. Stringent criteria with respect to the composition of fuel mix in power generation do not seem to be in line with 
such a position. Therefore, in the businessman's variant of the Triptych approach no strict criteria have been set but instead it was assumed that the composition of the fuel mix would be constant. The emphasis on flexibility and market-based solutions in the businessman's value-orientation reminds of the strong commitment to such solutions in the IPCC A1 storyline, which is a storyline of globalisation and rapid economic growth. We will, therefore, take the businessman's view on a desirable level and term of convergence of per capita emissions in the domestically oriented sectors from this storyline. Our businessman thinks of long-term solutions that will reduce global greenhouse gas emissions to acceptable levels by the end of this century. Therefore, we set the businessman's preference for the year of convergence of domestic per capita emissions at 2100. In their interpretation of the A1 storyline the IMAGE team (2001) projects the average level of per capita domestic emissions in the OECD as 2.1 ton $\mathrm{CO}_{2}$ by that year.

Third, we will specify the campaigner's preferences. His constant plea for a rapid transition to a carbon-free economy inspired the formulation of criteria for the fuel mix in power generation. This has a strong accent on renewable energy. We peg his preference for the 2015 fuel mix in power production as a reduction by half of power production from solid and liquid fossil fuels, a constant output of gas-based electricity, a phasing out of nuclear capacity by that year, and a filling in of the created gap by renewable sources. The level and timing of convergence of domestic per capita emissions adhered to by the campaigner we set at 1.7 ton $\mathrm{CO}_{2}$ per capita in the domestic sectors in 2100 , as in the B1 scenario (IMAGE team, 2001).

Finally, our characterisation of the survivor resembles the position of a representative of a developing country who underlines Annex I responsibility. His country will be hit hardest by climate change and thus, benefit comparatively more from mitigation efforts than industrialised countries. ${ }^{2}$ Therefore, we distinguished between criteria for fuel mix in power generation for rich (Annex I) countries on the one hand and for poor (non-Annex I) countries on the other. The criteria for fuel mix in power generation in Annex I countries we made equal to the criteria chosen from the campaigners' perspective. The criteria for non-Annex I have been derived from IEA's World energy Outlook (2000) in which projections for electricity generation capacity in the developing countries as a whole have been made. In projections for 2020, a tripling of coal-based capacity is foreseen in the developing countries. Oil-based capacity will increase, although its share in electricity output is likely to decline. Gas-based capacity in developing countries doubles as does nuclear capacity according to this projection. Although renewables may play an important role in providing electricity to remote, off grid locations as part of rural electrification programmes, their projected share in developing countries' electricity is modest, slightly over $1 \%$. The criteria for fuel mix in the survivor's case are mostly derived from these projections. Coal is used to balance the budget making up for any electricity production growth over what can be accommodated by the other sources. 
The level and timing of convergence of per capita emissions in the domestic sectors is taken from the (environmentally oriented) B1 scenario, which is inspired by the concerns among many countries vulnerable to the consequences of climatic change. The year of convergence is set at 2050, however, because voices advocating a rapid redistribution of rights to the global atmosphere are stronger among non-Annex I Parties. The IMAGE team's (2001) interpretation of the B1 scenario projects for 2050 an average OECD level of per capita emissions in the domestic sectors of 3.8 ton $\mathrm{CO}_{2}$. Table VIII shows targets, total $\mathrm{CO}_{2}$ emissions and total emissions per capita for each of the four value-orientations. Minimum and maximum values over the four value-orientations are given in Table IX. The range in the policy variables over the four value-orientations is smaller than the range resulting from cross-combining all valueloaded assumptions (Table VI).

\section{Uncertainty}

Apart from the selected highly valueladen parameters, which we dealt with above, the Triptych approach also contains parameters and input data that are less valueladen but still rather uncertain. In this section we will characterise and quantify these uncertainties using the NUSAP-method. The NUSAP-method was proposed by Funtowicz and Ravetz (1990) as a tool to systematically assess and communicate various dimensions of uncertainty. The method entails specification of Numeral, Unit, Spread, Assessment and Pedigree for data. The Numeral is usually an ordinary number, but when appropriate it can be a more general quantity, such as the expression "a million". Second comes Unit, which may be of the conventional sort, but which may also contain extra information, such as the date at which the unit is evaluated (most commonly with money). The middle category is Spread, which generalises from the "random error" of experiments or the "variance" of statistics. It is usually conveyed by a number (either, $\pm \%$ or "factor of"). This brings us to the more qualitative side of the NUSAP expression. The next category is Assessment; this provides a place for a concise expression of the salient qualitative judgements about the information. In the case of statistical tests, this might be the significance level; in the case of numerical estimates for policy purposes, it might be the qualifier "optimistic" or "pessimistic". Spread and Assessment together give information on the inexactness of a number. Finally, we have the Pedigree, which is an evaluative description of the mode of production (and where relevant, of anticipated use) of information. The pedigree or origin of a number provides an indication of its unreliability.

In Appendix II, we will specify the inexactness of the various parameters and input data in the form of probability density functions (PDFs), reflecting Spread and Assessment, on the base of literature and expert judgement. The PDFs were used as input for the Monte Carlo simulations. In the following we will discuss the 


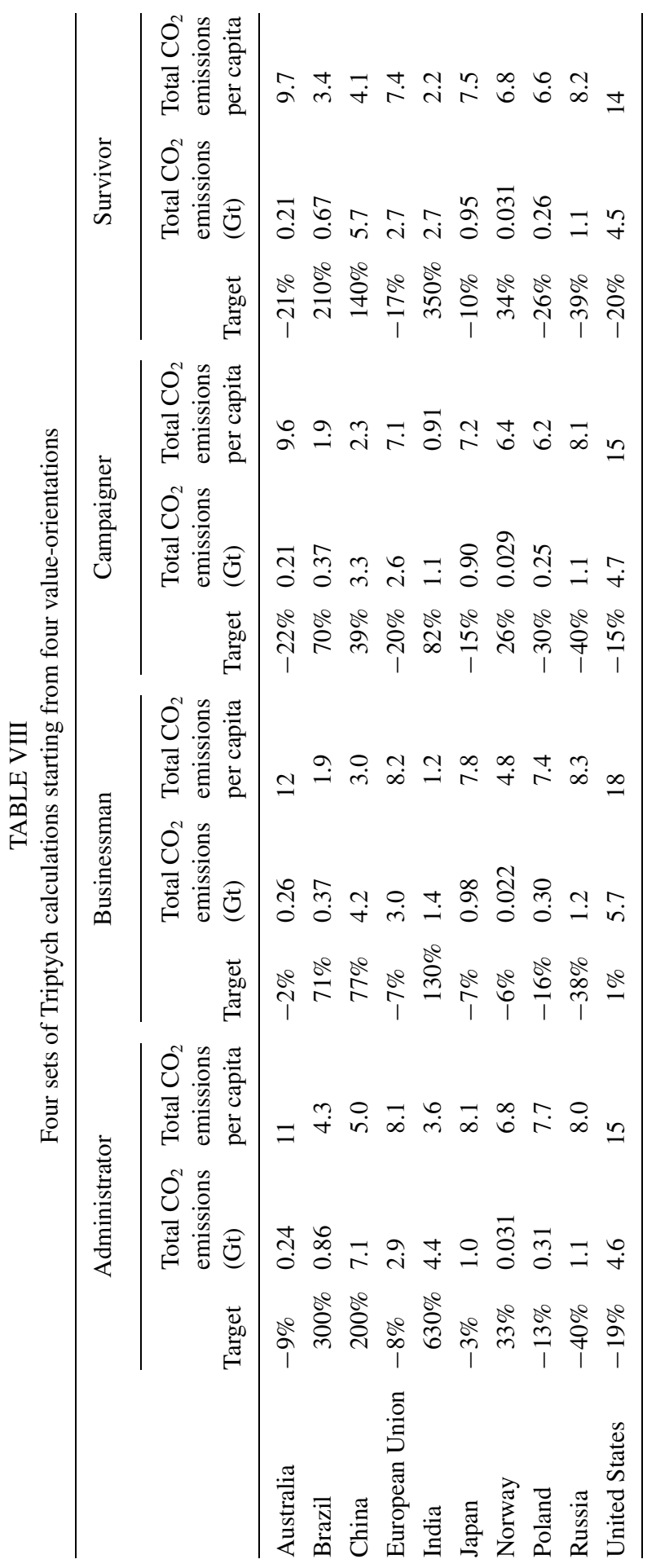


TABLE IX

Total range in three policy variables over four value-orientations in the Triptych approach

\begin{tabular}{|c|c|c|c|c|c|c|}
\hline & \multicolumn{2}{|c|}{ Target } & \multicolumn{2}{|c|}{$\begin{array}{l}\text { Total } \mathrm{CO}_{2} \\
\text { emissions (Gt) }\end{array}$} & \multicolumn{2}{|c|}{$\begin{array}{l}\text { Total } \mathrm{CO}_{2} \text { emissions } \\
\text { per capita }(\mathrm{t})\end{array}$} \\
\hline & Minimum & Maximum & Minimum & Minimum & Maximum & Minimum \\
\hline Australia & $-22 \%$ & $-2 \%$ & 0.21 & 0.26 & 9.6 & 12 \\
\hline Brazil & $70 \%$ & $300 \%$ & 0.37 & 0.86 & 1.9 & 4.3 \\
\hline China & $39 \%$ & $200 \%$ & 3.3 & 7.1 & 2.3 & 5.0 \\
\hline European Union & $-20 \%$ & $-7 \%$ & 2.6 & 3.0 & 7.1 & 8.2 \\
\hline India & $82 \%$ & $630 \%$ & 1.1 & 4.4 & 0.91 & 3.6 \\
\hline Japan & $-15 \%$ & $-3 \%$ & 0.90 & 1.0 & 7.2 & 8.1 \\
\hline Norway & $-6 \%$ & $34 \%$ & 0.022 & 0.031 & 4.8 & 6.8 \\
\hline Poland & $-30 \%$ & $-13 \%$ & 0.25 & 0.31 & 6.2 & 7.7 \\
\hline Russia & $-40 \%$ & $-38 \%$ & 1.11 & 1.2 & 8.0 & 8.3 \\
\hline United States & $-20 \%$ & $1 \%$ & 4.5 & 5.7 & 14 & 18 \\
\hline
\end{tabular}

unreliability of the input, indicated by the Pedigree, using a method as presented by Risbey et al. (2001).

For each of the input variables of the Triptych approach we made an assessment of the unreliability by focusing on the pedigree of the input data and parameters. Four dimensions of the pedigree have been included in a method that has been presented by Risbey et al. (2001) who based it on Funtowicz and Ravetz (1990). The dimensions include the proxy of the data, their empirical underpinning, the method and the validation. Each of these four dimensions of the pedigree may be scored on a scale of $0-4$. Table $X$ summarises the four dimensions of the pedigree, and shows what the score $0-4$ on each of these dimensions imply.

The scores on each of the dimensions may be summarised and aggregated in one overall valuation called the strength. The strength is meant to indicate the scientific rigour of the data and can be interpreted as the opposite of unreliability. It is calculated as the sum of the scores on the separate dimensions divided by the maximum score (16). A maximum score of four on all dimensions thus leads to strength one, whereas parameters scoring zero on all dimensions are valued with strength zero.

Table XI presents the scores that we gave to most input data and parameters in the Triptych approach and the resulting strength. Each of the scores will be explained below.

\subsection{PROXY}

The proxy pedigree dimension refers to how good or close a measure the quantity that we measure is to the actual quantity about which we seek information. An 
TABLE X

Pedigree matrix based on Funtowicz and Ravetz (1990) and adapted by Risbey and et al. (2001)

\begin{tabular}{|c|c|c|c|c|}
\hline Score & Proxy & Empirical & Method & Validation \\
\hline 4 & $\begin{array}{l}\text { An exact measure of } \\
\text { the desired } \\
\text { quantity }\end{array}$ & $\begin{array}{l}\text { Controlled } \\
\text { experiments and } \\
\text { large sample direct } \\
\text { measurements }\end{array}$ & $\begin{array}{l}\text { Best available } \\
\text { practice in well } \\
\text { established } \\
\text { discipline }\end{array}$ & $\begin{array}{l}\text { Compared with } \\
\text { independent } \\
\text { measurements of } \\
\text { the same variable } \\
\text { over long domain }\end{array}$ \\
\hline 3 & Good fit or measure & $\begin{array}{l}\text { Historical/field data, } \\
\text { uncontrolled } \\
\text { experiments, small } \\
\text { sample direct } \\
\text { measurements }\end{array}$ & $\begin{array}{l}\text { Reliable method } \\
\text { common within } \\
\text { established } \\
\text { discipline; best } \\
\text { available practice } \\
\text { in immature } \\
\text { discipline }\end{array}$ & $\begin{array}{l}\text { Compared with } \\
\text { independent } \\
\text { measurements of } \\
\text { closely related } \\
\text { variable over } \\
\text { shorter period }\end{array}$ \\
\hline 2 & $\begin{array}{l}\text { Well correlated but } \\
\text { commonalities in } \\
\text { measure }\end{array}$ & $\begin{array}{l}\text { Modelled/derived } \\
\text { data; indirect } \\
\text { measurements }\end{array}$ & $\begin{array}{l}\text { Acceptable method } \\
\text { but limited } \\
\text { consensus on } \\
\text { reliability }\end{array}$ & $\begin{array}{l}\text { Measurements not } \\
\text { independent proxy } \\
\text { variable limited } \\
\text { domain }\end{array}$ \\
\hline 1 & $\begin{array}{l}\text { Weak correlation but } \\
\text { commonalities in } \\
\text { measure }\end{array}$ & $\begin{array}{l}\text { Educated guesses } \\
\text { indirect approx. } \\
\text { rule of thumb } \\
\text { estimation }\end{array}$ & $\begin{array}{l}\text { Preliminary methods; } \\
\text { unknown } \\
\text { reliability }\end{array}$ & $\begin{array}{l}\text { Weak and very } \\
\text { indirect validation }\end{array}$ \\
\hline 0 & $\begin{array}{l}\text { Not correlated and } \\
\text { not clearly related }\end{array}$ & Crude speculation & No discernible rigour & $\begin{array}{c}\text { No validation } \\
\text { performed }\end{array}$ \\
\hline
\end{tabular}

TABLE XI

Scores on four dimensions of the pedigree and strength of input data and parameters in the Triptych approach

\begin{tabular}{llllll}
\hline & Proxy & Empirical & Method & Validation & Strength \\
\hline Energy-intensive industry & & & & & \\
$\quad \mathrm{CO}_{2}$ emission data & 3 & 3 & 4 & 0 & 0.6 \\
$\quad$ Growth physical production & 4 & 1 & 2 & 1 & 0.5 \\
$\quad$ Efficiency improvement & 4 & 1 & 2 & 2 & 0.6 \\
$\quad$ \& decarbonisation & & & & & \\
Electricity generation & & & & & 0.8 \\
$\quad$ Electricity output & 4 & 3 & 4 & 2 & 0.5 \\
$\quad$ Growth GDP & 4 & 1 & 2 & 1 & 0.8 \\
$\quad$ Carbon emission factor & 3 & 3 & 4 & 2 & 0.6 \\
Domestic sectors & & & & & 0.7 \\
$\quad$ CO ${ }_{2}$ emission data & 3 & 3 & 4 & 0 & 0.6 \\
$\quad$ Population data & 4 & 3 & 4 & 0 & \\
$\quad$ Population projection & 4 & 2 & 4 & 0 & \\
\hline
\end{tabular}


exact measure will be scored four, a good fit or measure three, a well correlated variable not measuring the same thing two, a weakly correlated variable one, and an uncorrelated variable zero.

For almost all input data and parameters the indicators we use are an exact measure of the quantity we are interested in. This is true for the data on electricity output and on population size, but also for the projections included. Projections of growth of population, GDP and physical production and on energy efficiency and decarbonisation all project just the variables we are interested in: no proxies are used to estimate them. Therefore, the proxy-scores of these variables are rated four. Only $\mathrm{CO}_{2}$ emission data are not measured directly but instead estimated from activity information that is well correlated and score three on the proxy dimension. Furthermore, in order to estimate carbon emission from fuel combustion, the carbon emission factor has been determined in other samples of the fossil fuels, which can be considered a more or less good measure for the fossil fuel that is actually combusted. Therefore, we score the proxy of the carbon emission factor three.

\subsection{THE EMPIRICAL DIMENSION}

The empirical dimension of the pedigree refers to the degree to which direct observations are used to estimate the variable. Better observational data result in a higher score. Controlled experiments and large sample sizes will be scored four, historical and field data three, modelled or derived data two, more or less educated guesses one, and crude speculation zero.

Of all the input variables in the Triptych approach only the carbon emission factors of various fossil fuels have been estimated in controlled experiments. However, since the number of experiments and sample sizes are small (Turkenburg and van der Sluijs, 2000) we rate their empirical dimension three. Most other data, such as data on $\mathrm{CO}_{2}$ emissions, population or electricity production are historical and score three as well. Population projections for a year as close as 2015 are derived from today's population sizes and therefore have some empirical basis, which is why we score the empirical dimension two. The projections on growth of physical production and GDP and future efficiency improvement and decarbonisation are considered educated guesses, and we rate them with a one.

\subsection{METHOD}

The method is the third dimension of the pedigree. Methodological quality refers to the degree to which peers approve of the method applied. Best available practices in well-established disciplines would score four on this metric. A reliable method common within an established discipline or best available practice in an immature discipline scores three. An acceptable method on which limited consensus regarding 
the reliability exists is valued two, preliminary methods with an unknown reliability one, and methods with no discernible rigour zero.

The determination of electricity production takes place through standard measurements at electricity plants, which is a straightforward procedure that we score four. The determination of the carbon emission factor is also a well-established practice for which standard laboratory routines exist. We value its method with a four. The method for the compilation of $\mathrm{CO}_{2}$ emission data from activity data and emission factors has been approved widely by peers in the field, and we score the method four as well. The estimation of present population sizes and projection of future populations is somewhat difficult. Although census practices are well established and peer-approved in most countries of the developed world, in a lot of developing countries many people remain uncounted, and still room for improvement of census practices exists. In the field of population projections also methodological controversies exist (Keilman, 1997) and the field seems insufficiently mature to have learned from erroneous projections in the past. Both population data and population projection score three on the methodological dimension of the pedigree. The determination of future growth rates of physical production and GDP and of efficiency improvement and decarbonisation has been done in a rule-of-thumb-like way. This may be an acceptable method but consensus on the reliability is limited, and we score the method two.

\subsection{VALIDATION}

The validation pedigree dimension refers to the degree to which one has been able to crosscheck the data against independent sources. Comparisons with independent measurements of the same variable over a long time period lead to score of four. A three results if the independent measurements regard a closely related variable and/or are being carried out over a shorter period. Measurements of a variable that is not independent over a limited domain scores two, a weak and vary indirect validation one, and a zero results if no validation is performed whatsoever.

Most of the input data and parameters in the Triptych approach, although collected by renowned institutes, have not been cross-checked by these institutes (IEA, 2001; Zlotnik, 2001, personal communication). Therefore, the validation of population and emission data is rated zero here. As for electricity data, however, it is relatively easy for the national statistics institutes where the data originate to perform some validation, since they may cross-check electricity production data against consumption figures. The validation of the electricity output data is, therefore, scored two. Growth of physical production and GDP have been checked with respect to their order of magnitude in the sense that growth in developing countries is larger than in the industrialised world. The validation of these parameters can be rated one. The combined rate for improvement of energy-efficiency and decarbonisation has been cross-checked with the historical reduction trend of 
energy-efficiency improvement and we rate the validation two. The carbon emission factor of the various fossil fuels were taken from (Houghton et al., 1996). They were based on values from very few studies and cannot be considered as rigorously cross-checked, but its validation is certainly better than the validation of future data ever can be. Therefore, we rate the validation two.

\subsection{STRENGTH}

Our assessment of the pedigree of the various parameters and input data can be expressed in the strength in which the separate scores on the four dimensions may be summarised. This reveals that statistical data on population and electricity output are strongest, followed immediately by data on $\mathrm{CO}_{2}$ emissions. The value of the rate for efficiency improvement and decarbonisation in the energy-intensive industry is considerably weaker. Growth rates for the economy and physical production in the energy-intensive industry are the weakest parameters, implying that the chance of personal views affecting their outcome are largest.

\section{Results}

We will now describe the results of four Monte Carlo simulations, one for each of the value-orientations. Values for the valueladen parameters were differentiated over the four value-orientations according to Table VII. The values of the remaining parameters and input data were varied according to the probability density functions, for which an argumentation can be found in Groenenberg (2002). Thus, four ranges of resulting reduction objectives were obtained for each of the countries included in the analysis. For the analysis we used Crystal Ball, which is a spreadsheet addon tool for forecasting, risk analysis, and optimisation by means of Monte Carlo analyses.

\subsection{UNCERTAINTIES IN RESULTING TARGETS}

Not surprisingly emission reduction targets resulting from the Triptych approach as applied from the administrator's, businessman's, campaigner's and survivor's valueorientations differ. As a consequence the overall change in emissions from the 10 countries by the year 2015 in the level of combustion related $\mathrm{CO}_{2}$ is $+45 \%,+11 \%$, $-6 \%$ and $+21 \%$ in the value-orientations of the administrator, the businessman, the campaigner and the survivor, respectively. We found that the differentiation of commitments varies over the four value-orientations (Figure 3). However, the ranking of countries remains fairly constant (Table XII), with the ranking in the businessman's case showing the most deviating pattern. In the following we will discuss differences in the outcome from the four value-orientations. 
TABLE XII

Ranking of countries' objectives in calculations from four perspectives

\begin{tabular}{lccccc}
\hline & Administrator & Businessman & Campaigner & Survivor & Average \\
\hline Russia & 1 & 1 & 1 & 1 & 1.0 \\
Poland & 3 & 2 & 2 & 2 & 2.3 \\
Australia & 4 & 6 & 3 & 3 & 4.0 \\
European Union & 5 & 4 & 4 & 4 & 4.3 \\
United States & 2 & 7 & 5 & 5 & 4.8 \\
Japan & 6 & 3 & 6 & 6 & 5.3 \\
Norway & 7 & 5 & 7 & 7 & 6.5 \\
China & 8 & 9 & 8 & 8 & 8.3 \\
Brazil & 9 & 8 & 9 & 9 & 8.8 \\
India & 10 & 10 & 10 & 10 & 10 \\
\hline
\end{tabular}

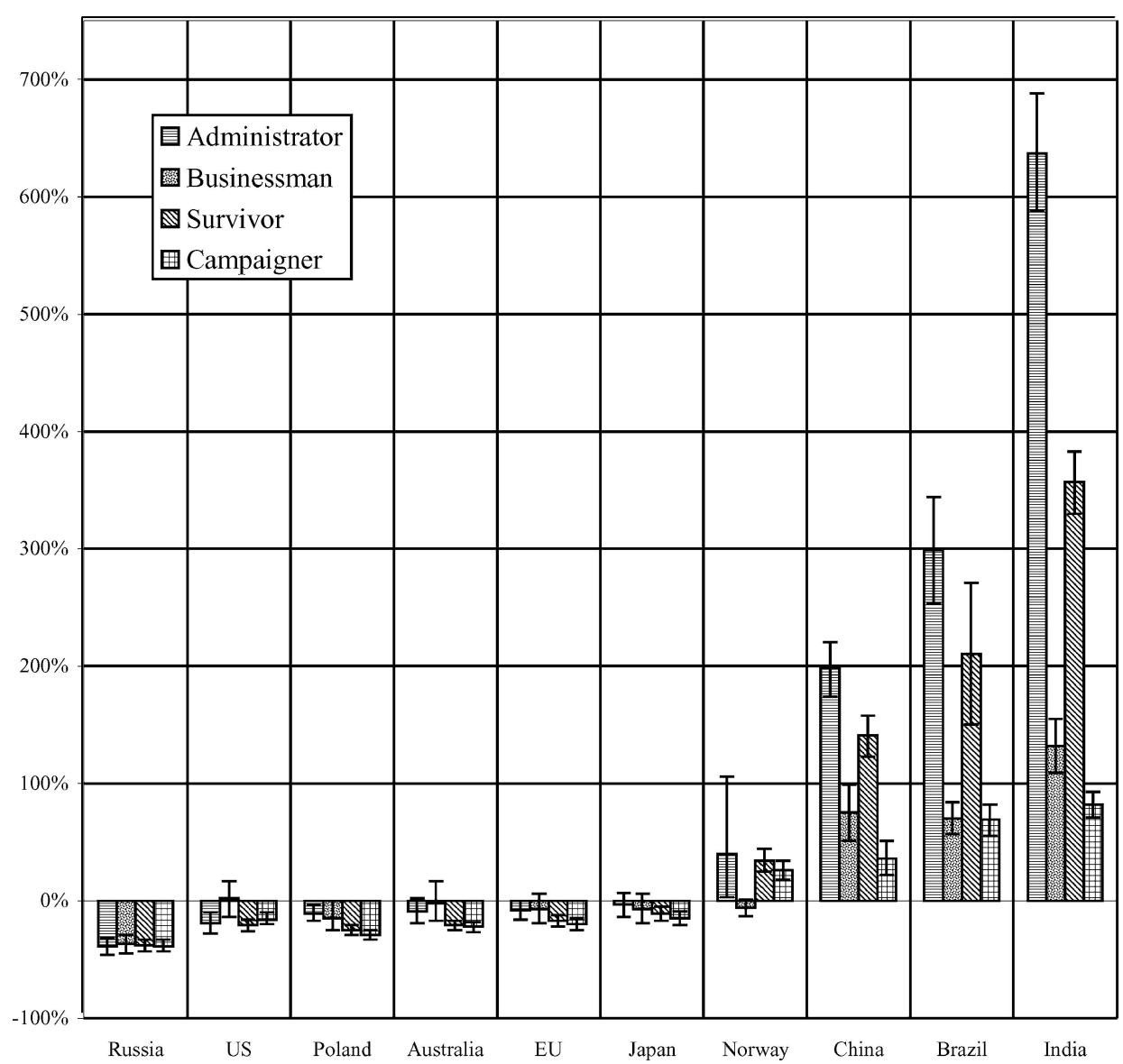

Figure 3. Resulting objectives from the Triptych approach applied from four value-orientations. Error bars indicate $95 \%$ confidence intervals. 
A brief glance at Figure 3 reveals that uncertainties in resulting objectives as indicated by the error bars vary over the four value-orientations. The range in resulting objectives may be relatively small, such as for Australia in the survivor's valueorientation or quite large as for Brazil in the same value-orientation. For Annex I countries ranges resulting from uncertainties in general are around 10\%-points for targets calculated from the campaigner's and survivor perspectives, between 15 and 20\%-points in the administrator's case and between 15 and 35\%-points in the businessman' case. For non-Annex I countries these ranges vary quite a bit over the four value-orientations. They are smallest (between 20 and 30\%-points) in the campaigner's case, and up to over $100 \%$ in the administrator's and survivor's cases.

Figure 3 also gives an indication of the contribution to the spread in outcome resulting from uncertainty on the one hand and value-loading on the other. For Annex I countries the spread resulting from uncertainty is in the same order of magnitude as the spread resulting from value-loading. For non-Annex I countries, however, the spread resulting from uncertainty is much smaller than the spread from value-loading.

\subsection{SOURCES OF UNCERTAINTY}

Apart from the variation in the outcome of Triptych calculations introduced by the valueloading of assumptions on convergence in the domestic sectors and fuel mix in power generation, additional variation is introduced by the remaining parameters and input data. These include growth assumptions for the population, the economy and production in the energy-intensive industry, assumptions on future energy efficiency improvement and decarbonisation in the energy-intensive industry, statistical data on emissions, population and electricity output and emission factors. Figure 3a-3d shows how uncertainties in the remaining input data and parameters contribute to the variance in the resulting reduction objectives. The figure only shows contributions over $1 \%$. An interesting finding is that contributions are not similar over the four cases.

In the administrator's and businessman's cases variance in the results largely stems from uncertainties in the economic growth rate. This is because assumptions on the growth of the economy determine emissions in the power generating sectors.

In the Triptych calculations carried out from the campaigner's and survivor's slant a different pattern of the contribution of the various parameters to the variance in the results pops up. Here the assumptions on growth of the energy intensive industry and the combined rate of efficiency improvement and decarbonisation become major contributors to the variance in the outcome.

In brief, uncertainties on future growth of the economy and industrial production and energy efficiency are major contributors to the variance in the resulting emission 


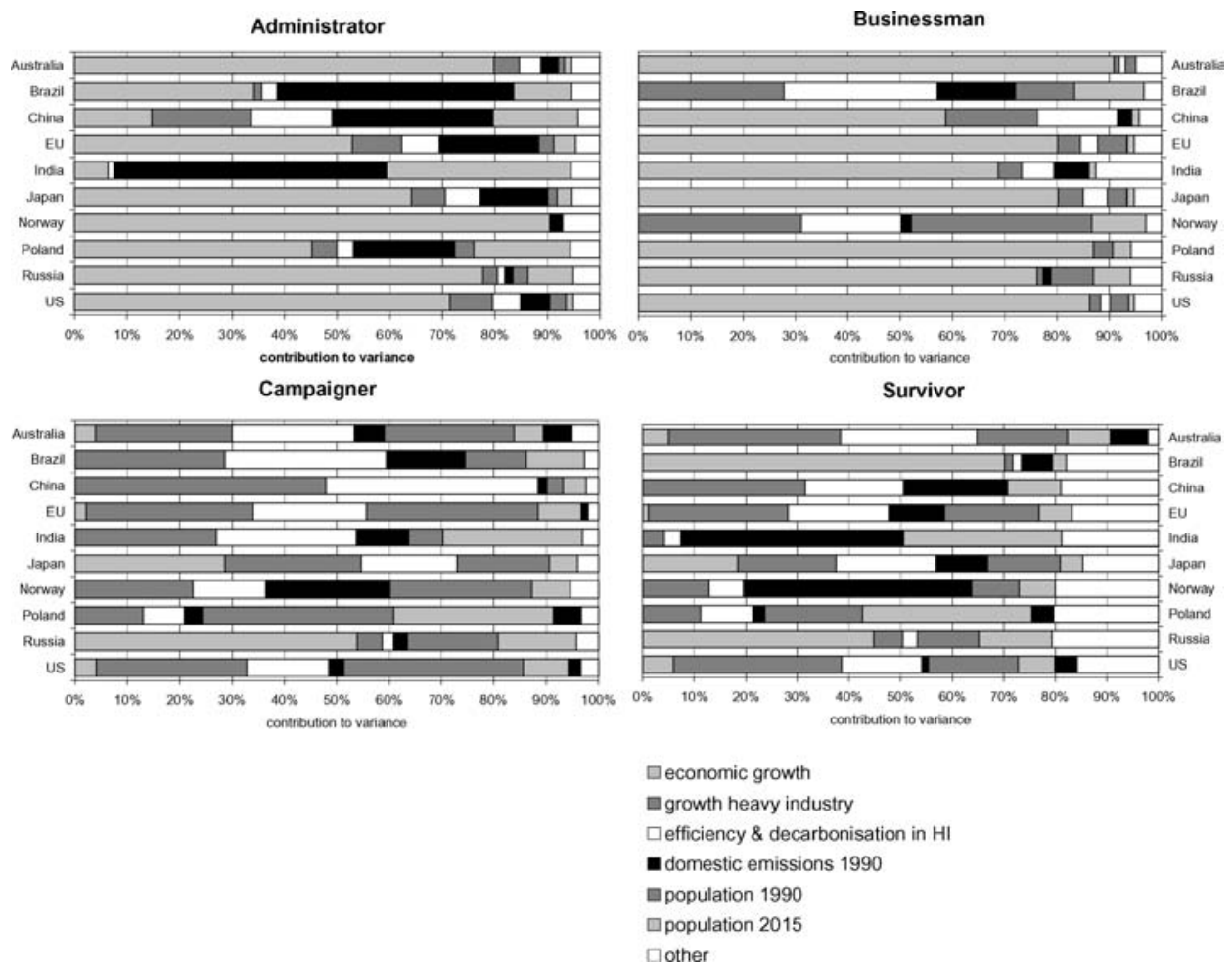

Figure 4. Contribution to variance in resulting targets of a number of parameters and data in the Triptych approach applied from four value-orientations.

objectives. The magnitude of these contributions, however, depends very much on the value-orientation chosen. Note that a more detailed explanation of Figure 4 can be found in Groenenberg (2002).

In the identification of major uncertainties in the Triptych approach it seems wise not only to consider the contribution to the variance in outcome but also to pay attention to the strength of the various inputs, as discussed in Section 4. In general, it can be stated that baseline assumptions on the growth of the economy and physical production in the energy-intensive industry need to be chosen based on maximal research and consultation of stakeholders, since they are the weakest parameters (see Table XI).

\section{Discussion}

In our discussion we will first make some remarks on the distinction we made between valueladen parameters and more objective input data parameters. We will also address the link between our calculations and the link with political 
reality i.e. Parties' positions in climate negotiations. Next the balance between the precision of the approach and user-friendliness will be dealt with. This point is connected with a number of shortcomings of the Triptych approach. We will also discuss briefly under what conditions a Triptych-like approach could be of use in the global context, including both industrialised and developing countries.

First of all, in our analysis it was important to distinguish between valueladen parameters on the one hand and the input data and parameters that can be measured more objectively on the other. In fact, there is a whole spectrum of hybrids between obviously subjective parameters (such as the desirable year of convergence of domestic per capita emissions) and the data and parameters that can be established rather objectively (such as the current size of a population). Parameters that take an intermediate position are in particular growth assumptions for the economy and for physical production in the energy-intensive industry. On the one hand these may be considered autonomous variables that are hard to influence. On the other hand the specification of baseline assumptions on economy and production levels can be made in a normative manner depending on the value-orientation of the user. This normative character may be even stronger for the rate of efficiency improvement and decarbonisation in the energy-intensive industry, since specific policies may be formulated to affect these. However, both growth assumptions and assumptions on efficiency improvement have also clear autonomous elements and we chose not to include them in the specification of value-orientations. This enabled us to include them in the uncertainty analyses that we carried out within the calculations for each of the four value-orientations.

Second, one may wonder to what extent cultural variation is captured sufficiently by a limited number of ideal-types. This point has been put forward by various authors commenting on traditional cultural theory as used by Schwarz and Thompson (1990). Naturally the same objection holds for Ravetz' modified cultural theory (Ravetz, 2001). While the typology spans up a well recognizable spectrum of value-orientations, we did not pretend to be exhaustive. We demonstrated that cross-combining all valueladen parameters randomly results in a range of targets (Table VI) that exceeds the range over the four valueorientations (Table IX). However, when combining randomly, inconsistent combinations are included, which may result in an overestimation of the range. Furthermore, it has not been our intention to cover the whole range of worldviews around the globe. We selected four typical value-orientations merely as an analytical tool to explore to what extent the outcome of Triptych calculations depend on value-orientation. Likewise our specification of the four valueorientations as particular choices for valueladen parameters mainly serves as an illustration, and we certainly do not mean to lump together all businessmen or all campaigners.

Third, in close connection to this point the reader may be curious as to how Parties' positions in climate negotiations relate to the value-orientations elaborated. 
As we have opted for an ideal-typical approach in this analysis, there is no immediate correspondence. Any real life actor will be some kind of a hybrid rather than an extreme on the spectrum. The lack of such a clear correspondence limits the practical value of this study somewhat. This could be overcome by doing a comprehensive bottom-up elicitation amongst the relevant parties and stakeholders in order to define a set of value-orientations that correspond more closely to actual positions in the climate negotiations. However, that would be a highly resource-intensive social science exercise, well beyond the scope of this study.

A fourth remark regards the relative simplicity of the Triptych approach. Should it be more detailed in order to better reflect reality? We argue that such is not the case. The Triptych approach has been designed to support decision-making regarding reduction and limitation objectives. Such an exercise seems to bear a strong resemblance to the building of a mitigation scenario, in which climate policies are assumed to restructure greenhouse gas emissions. Nevertheless, there are important differences. Contrary to a mitigation scenario, an approach for differentiating commitments is designed particularly to serve as an input for negotiations on future allowed emissions. This means that it must be highly transparent and understandable for a non-expert audience. This puts limits on the complexity of such a differentiation approach. Inevitably, simplifications have to be made with respect to activity levels in various sectors of the economy, whereas in complex models such activity levels might be estimated in a more refined manner. Furthermore, a decision-support tool must offer some choices to the negotiator. In the Triptych approach this scope for choice crystallises as the fuel mix for power generation in the target year and year and level for per capita emissions in the domestic sectors. At the same time, the number of choices must be restricted in order not to overwhelm the user with a large number of parameters whose value is difficult to assess without extensive knowledge of the field. Therefore, some starting points must be made explicit. In the Triptych approach these are the growth assumptions for population size, for the electricity output and emissions in heavy industry.

Obviously, the Triptych approach as presented here has some shortcomings that make it problematic to use it at the global level. It would be desirable for instance to gain a better understanding of the uncertainties about future growth in the energy-intensive industry and the power-producing sector, since these may diverge substantially world wide and will substantially affect resulting emission objectives. Furthermore, the criteria applied in the power-producing sector do not seem to be applicable for the wide global variety of fuel mixes in power generation. It is recommended to adjust the criteria in a way that takes into account countries' potential for renewable energy as well as their indigenous fossil fuel supplies. In addition, the approach needed to be adjusted so as to take more account of international differences in industrial energy efficiency and the emissions of non$\mathrm{CO}_{2}$ greenhouse gases. 
In fact, we have juse published work on an adjusted Triptych approach (by the name 'Global Triptych', see Groenenberg et al. (2005)), in which these shortcomings have been overcome to a certain extent. In it we define longterm (2050) policy targets for energy efficiency in the energy-intensive industry, greenhouse gas intensity of electricity production and per capita emissions in the domestic sectors. Bottom-up information on reduction opportunities is used to quantify the targets. We adjusted these policy targets, as well as the assumptions on population and production growth, to quantify the effect on emission objectives and global emissions. Furthermore global emissions are compared to an emission profile for stabilising atmospheric concentrations at 450 ppmv.

Finally, we wish to underline that the large effect that uncertainties in baseline assumptions and statistical data have on the outcome of Triptych calculations cannot refute the fact that national circumstances regarding reduction opportunities for greenhouse gas emissions vary widely. The large effect that e.g. assumptions on future fuel mix in power generation and energy efficiency have make it al the more important to take differences between countries at these points into consideration while ranking countries in a differentiation of commitments. However, some caution should be observed in awarding absolute value to calculated reduction objectives.

\section{Conclusions}

Valueloading and uncertainty are important issues in any approach to differentiation of emission reduction commitments. In this study we took the Triptych approach as a case study to demonstrate how resulting emission reduction objectives may vary as a result from valueloading and uncertainty, the latter split up into unreliability and inexactness.

Highly valueladen assumptions in the Triptych calculation scheme comprise (1) assumptions on fuel mix in the electricity producing sector in the target year, (2) the year in which per capita emissions in the domestic sectors are taken to converge and (3) the level at which this convergence should take place. We tested the effect of highly valueloaded assumptions on the outcome in two manners. First, we used sensitivity analyses for each of these assumptions separately. Next, we specified bundled assumptions for highly valueloaded parameters in each of four value-orientations. We found that the effect of these highly valueladen assumptions on the outcome is large. Targets for Annex I countries differed up to around $20 \%$-points over various value-orientations. For one developing country the growth objective differs by the order of seven, and the emission allowance by the order of four.

It is possible that other consistent combinations of highly valueloaded assumptions may result in targets that are outside the range that we based on 
the value-orientations. Therefore, some care should be observed when assessing valueloading based on a limited number of value-orientations only. Resulting objectives are affected to a large extent as well by uncertainties in the other input data and parameters. For Annex I countries ranges in the outcome resulting from uncertainties are between 10 and 35\%-points depending on the valueorientation chosen. For non-Annex I countries these ranges are a lot larger and may be between 20 and 120\%-points. The contribution of uncertainties in the various parameters and input data to the variance in the resulting target depends on the value-orientation chosen. Parameters and data that affect the outcome to a large extent are baseline assumptions for the size of the economy, for physical production levels, efficiency improvement and decarbonisation in the energyintensive industry. Especially the parameters and input data for which scientific underpinning is weaker should be considered carefully when specifying them. These are especially baseline assumptions on growth of the economy and physical production.

The relevance of uncertainty and value-loading is not the same for Annex I and non-Annex I countries. For Annex I countries the spread in the calculated targets resulting from uncertainty is more or less of the same order of magnitude as the spread resulting from value-loading. For non-Annex I countries however the spread from value-loading is much larger than the spread resulting from uncertainty.

An important result is that the ranking of countries within the calculated differentiation of commitments remains roughly the same, with the exception of the ranking of countries that resulted from calculations from the businessman's perspective. This demonstrates that the Triptych approach retains its value for the issue of differentiation of commitments.

Finally, we conclude that a scheme for differentiating emission objectives should make explicit policy variables included in the scheme and the resulting emission objectives. Consensus on such policy variables will be vital for the adoption of the outcome any differentiation scheme.

\section{Acknowledgments}

The authors are grateful to Penny Kloprogge, Kornelis Blok, Jerry Ravetz, Paul Baer and Bert de Vries who provided valuable comments on earlier drafts of this article.

\section{Appendix I}

We used the following algorithms in our approach for differentiation of commitments. 
THE ENERGY-INTENSIVE INDUSTRY

The allowance in the energy-intensive industry were calculated according to

$$
A_{\text {ind }, 2015}=E_{\text {ind, } 1990} *(1+g)^{n} *(1-e i)^{n}
$$

in which: $A_{\text {ind,2015 }}=$ partial allowance for heavy industry in the year 2015 $\left(\mathrm{Mt} \mathrm{CO}_{2}\right) ; E_{\mathrm{ind}, 1990}=$ emission from heavy industry in the year $1990(\mathrm{Mt}$ $\left.\mathrm{CO}_{2}\right) ; g=$ annual growth rate of physical production (\%); $e i=$ annual efficiency improvement (expressed as the reduction of the average specific energy consumption).

\section{THE POWER-PRODUCING SECTOR}

Total electricity consumption in 2015 was estimated according to

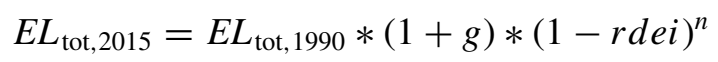

Electricity generated by various sources in 2015 was calculated as follows:

$$
\begin{aligned}
& E L_{\text {coal }, 2015}=70 \% \times E L_{\text {coal }, 1990} \\
& E L_{\mathrm{liq}, 2015}=70 \% \times E L_{\mathrm{liq}, 1990} \\
& E L_{\text {nucl }, 2015}=E L_{\text {tot }, 2015} \times \frac{E L_{\text {nucl, } 1990}}{E L_{\text {tot }, 1990}} \\
& E L_{\text {renew }, 2015}=E L_{\text {renew }, 1990}+0.08 \times E L_{\text {tot }, 2015} \\
& E L_{\mathrm{CHP}, 2015}=\min \left(E L_{\mathrm{tot}, 2015}-E L_{\mathrm{coal}, 2015}-E L_{\mathrm{liq}, 2015}-E L_{\mathrm{nucl}, 2015}\right. \\
& \text { - } E L_{\text {renew }, 2015}, 0.15 \times E L_{\text {tot }, 2015)} \\
& E L_{\mathrm{gas}, 2015}=\min \left(E L_{\mathrm{tot}, 2015}-E L_{\mathrm{coal}, 2015}-E L_{\mathrm{liq}, 2015}-E L_{\mathrm{CHP}, 2015}\right. \\
& \left.-E L_{\text {renew,2015 }}-E L_{\mathrm{CHP}, 2015}, 0\right)
\end{aligned}
$$

in which $E L_{\text {tot,y }}=$ total electricity consumption in year $y(\mathrm{PJ}) ; E L_{x, y}=$ electricity consumption by fuel $x$ in year $y(\mathrm{PJ}) ; g=$ annual GDP growth rate; $r d e i=$ reduction rate for reduced demand due to efficiency improvements; $n=$ number of years.

We estimated 2015 power generation efficiencies by interpolating between the 1990 efficiencies and a convergence level for the efficiency in 2030:

$$
\eta_{x, 2015}=\eta_{x, 1990}+\left(\eta_{x, \mathrm{conv}}-\eta_{x, 1990}\right) \times \frac{25}{40}
$$

in which $\eta_{x, y}=$ generation efficiency in conventional capacity based on fuel $x$ (solids, liquids or gas) in year $y(\%) ; \eta_{x \text {,conv }}=$ conversion efficiency for the year 2030 in capacity based on fuel $x(\%)$. 
Primary energy use in conventional and in CHP capacity was calculated as

$$
\begin{aligned}
P E_{\mathrm{coal}, 2015} & =\frac{70 \% \times E L_{\mathrm{coal}, 1990}}{\eta_{\mathrm{coal}, 2015}} \\
P E_{\mathrm{liq}, 2015} & =\frac{70 \% \times E L_{\mathrm{liq}, 1990}}{\eta_{\mathrm{liq}, 2015}} \\
P E_{\mathrm{CHP}} & =\frac{E L_{\mathrm{CHP}, 2015}}{\eta_{\mathrm{CHP}, 2015}} \\
P E_{\mathrm{gas}} & =\frac{E L_{\mathrm{gas}, 2015}}{\eta_{\mathrm{gas}, 2015}}
\end{aligned}
$$

in which $P E_{x, y}=$ primary energy use of fuel $x$ in year $y(\mathrm{PJ}) ; \eta_{\mathrm{CHP}, 2015}=$ shadow efficiency in CHP (see Appendix B).

Finally, we determined the partial allowance for the power-producing sector:

$$
\begin{aligned}
A_{\text {coal }, 2015} & =P E_{\text {coal }, 2015} \times\left[\left(1-f_{b c}\right) \times e f_{h c}+f_{b c} \times e f_{b c}\right] \\
A_{\text {liq }, 2015} & =P E_{\text {liq }, 2015} \times e f_{\text {liq }} \\
A_{\text {gas }, 2015} & =P E_{\text {gas }, 2015} \times e f_{\text {gas }} \\
A_{\mathrm{CHP}, 2015} & =P E_{\mathrm{CHP}, 2015} \times e f_{\text {gas }} \\
A_{\text {power }, 2015} & =A_{\text {coal }, 2015}+A_{\text {liq }, 2015}+A_{\text {gas }, 2015}+A_{\mathrm{CHP}, 2015}
\end{aligned}
$$

in which $f_{b c}=$ share of brown coal in coal input in public electricity generation $(\%) ; e f_{x}=$ emission factor for fuel $x\left(\mathrm{Mt} \mathrm{CO}_{2} / \mathrm{PJ}\right) ; A_{\text {coal }, 2015}=$ allowance for coal based electricity in the year $2015\left(\mathrm{Mt} \mathrm{CO}_{2}\right) ; A_{\text {power,2015 }}=$ allowance for the powerproducing sector in the year $2015\left(\mathrm{Mt} \mathrm{CO}_{2}\right) ; A_{x, 2015}=$ allowance for electricity

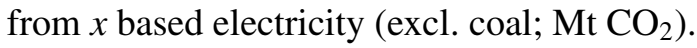

\section{THE DOMESTIC SECTORS}

The partial allowance for the domestic sectors in 2015 was based on a convergence of per capita allowances by the year 2030

$$
\begin{aligned}
a_{\mathrm{pc}, 2015} & =a_{\mathrm{pc}, 1990}-\left(a_{\mathrm{pc}, 1990}-a_{\mathrm{pc}, \mathrm{conv}, 2030}\right) \times \frac{25}{40} \\
A_{\mathrm{dom}, 2015} & =a_{\mathrm{pc}, 2015} \times P_{2015}
\end{aligned}
$$

in which $A_{\mathrm{pc}, 2015}=$ per capita allowance in the year $2015\left(\mathrm{Mt} \mathrm{CO}_{2}\right) ; A_{\mathrm{pc}, 2030}=$ convergence level for the per capita allowance by the year $2030\left(\mathrm{Mt} \mathrm{CO}_{2}\right) ; P_{2015}=$ population in the year 2015; $A_{\mathrm{dom}, 2015}=$ allowance for the domestic sectors in the year $2015\left(\mathrm{Mt} \mathrm{CO}_{2}\right)$. 


\section{Appendix II}

TABLE A1

Values and probability density functions for parameters and input data for the Triptych approach as in Groenenberg et al. (2001)

\begin{tabular}{|c|c|c|c|}
\hline \multirow[b]{2}{*}{ Parameter or input } & \multirow[b]{2}{*}{ Value } & \multicolumn{2}{|c|}{ Probability density function } \\
\hline & & Distribution & $\begin{array}{l}95 \% \text { confidence interval } \\
\text { or spread (min-max) }\end{array}$ \\
\hline \multicolumn{4}{|c|}{ Energy-intensive industry } \\
\hline $\mathrm{CO}_{2}$ emission data ${ }^{1}$ & & Normal & $\pm 10 \%$ \\
\hline \multicolumn{4}{|l|}{ Growth $^{2}$} \\
\hline \multicolumn{4}{|l|}{ OECD } \\
\hline Iron and steel & $0.7 \%$ & & $(-0.5-2.0 \%)$ \\
\hline Chemical & $1.8 \%$ & & $(0.0-3.5 \%)$ \\
\hline Refineries & $1.0 \%$ & & $(0.0-2.0 \%)$ \\
\hline Pulp and paper & $1.5 \%$ & & $(1.0-2.0 \%)$ \\
\hline Cement & $1.0 \%$ & & $(0.0-2.0 \%)$ \\
\hline \multicolumn{4}{|l|}{$\mathrm{EE} / \mathrm{FSU}$} \\
\hline Iron and steel & $0.1 \%$ & & $(-1.0-1.5 \%)$ \\
\hline Chemical & $1.0 \%$ & Triangular & $(-0.5-2.5 \%)$ \\
\hline Refineries & $1.0 \%$ & & $(0.0-2.0 \%)$ \\
\hline Pulp and paper & $1.5 \%$ & & $(0.5-2.5 \%)$ \\
\hline Cement & $1.0 \%$ & & $(-0.5-2.5 \%)$ \\
\hline \multicolumn{4}{|l|}{ DC } \\
\hline Iron and steel & $4.0 \%$ & & $(3.0-5.0 \%)$ \\
\hline Chemical & $4.1 \%$ & & $(3.0-5.5 \%)$ \\
\hline Refineries & $3.0 \%$ & & $(2.5-3.5 \%)$ \\
\hline Pulp and paper & $5.5 \%$ & & $(4.5-6.5 \%)$ \\
\hline Cement & $4.0 \%$ & & $(2.5-5.5 \%)$ \\
\hline Efficiency improvement & $1.5 \%$ & Triangular & $(1.5-2.5 \%)$ \\
\hline \multicolumn{4}{|c|}{ Electricity generation } \\
\hline Electricity output $^{3}$ & & Normal & $\pm 5 \%$ \\
\hline $\mathrm{CO}_{2}$ emission factors & & Normal & $\pm 3 \%$ \\
\hline Growth GDP & Various & Triangular & $\pm 1.5 \%$ - points \\
\hline \multicolumn{4}{|c|}{ Domestic sectors } \\
\hline $\mathrm{CO}_{2}$ emission data & & Normal & $\pm 10 \%$ \\
\hline Population data ${ }^{3}$ & & Normal & $\pm 5 \%$ \\
\hline Population scenario ${ }^{4}$ & & Triangular & \\
\hline OECD & & & $(100-105 \% \times$ value $)$ \\
\hline $\mathrm{EE} / \mathrm{FSU}$ & & & $(100-109 \% \times$ value $)$ \\
\hline $\mathrm{DC}$ & & & (99-107\% × value) \\
\hline
\end{tabular}

Data from ${ }^{1}$ (IEA, 1997a); ${ }^{2}$ (WEC, 1995); ${ }^{3}$ (IEA, 1997b, 1998); ${ }^{4}$ (UN, 1998). 


\section{Notes}

${ }^{1} \mathrm{~A}$ right to certain basic human needs is unmistakable, but two problems may arise when this concept is translated into allowable emission levels. First, concepts of what exactly basic needs are may vary among people who currently have different standards of living. Second, realising a certain standard of living will involve different emission levels in various parts of the world as a result of different national circumstances including economic structure, fuel mixes, technologies available, etc. Interpreting a right to minimum basic rights simply as equal per capita emission levels world wide does not do justice to the wide variety of national circumstances referred to in article 4.1 of the Convention.

${ }^{2}$ In contrast, the group of industrialised countries would prefer to continue emitting greenhouse gases and compensate losers in developing countries.

\section{References}

Baer, P.: 1998, "Cultural Theory" and its Application in Environmental Risk Perception. Working paper. Energy and Resources Group, University of California, Berkeley.

Baumert, K. A., Bhandar, R., and Kete, N.: 1999, What might a developing country climate commitment look like?, World Resources Institute, Washington, DC.

Berk, M., Hisschemöller, M., Mol, T., Hordijk, L., Kok, M., and Metz, B.: 2001, Strategieën voor langetermijn klimaatbeleid, de resultaten van het COOL-project, Nationaal Programma Mondiale Luchtverontreiniging en Klimaatverandering (NOP-II), Bilthoven, The Netherlands.

Blanchard, O., Criqui, C., Trommetter, M., and Vinguier, L.: 2001, Equity and Efficiency in Climate Change Negotiations: A Scenario for World Emission Entitlements by 2030, Cahier de Recherche No. 26, Institut d'economie et de politique de l'energie (IEPE), Grenoble, France.

Blok, K., Phylipsen, G. J. M., and Bode, J. W.: 1997, The Triptique Approach. Burden Differentiation of $\mathrm{CO}_{2}$ Emission Reduction Among European Union Member States, Utrecht University, Department of Science, Technology and Society, Zeist, The Netherlands.

Banuri, T., Göran-Mäler, K., Grubb, M., Jacobson, H. K., and Yamin, F.: 1996, 'Equity and social considerations', in Bruce, J. P., Lee, H., and Haites, E. F. (eds.), Climate Change 1995 - Economic and Social Dimensions of Climate Change, Contribution of Working Group III to the Second Assessment Report, Cambridge University Press, Cambridge.

Boholm, A.: 1996, 'Risk perception and social anthropology: Critique of cultural theory', Ethnos 61, 64-84.

Boyle, R. P. and Coughlin, R. M.:1994, 'Conceptualizing and operationalizing cultural theory', in Coyle, D. J. and Ellis, R. J. (eds.), Politics, Policy and Culture, Westview Press, Boulder.

den Elzen, M. G. J., Berk, M. M., Both, S., and Metz, B.: 2000, FAIR 1.0 (Framework to Assess International Regimes for differentiation of commitments): An interactive model to explore options for differentiation of future commitments in international climate policy making, National Institute for Public Health and the Environment, Bilthoven, The Netherlands.

Douglas, M.: 1982, Essays in the Sociology of Perception, Routledge \& Kegan Paul Ltd., London, Boston and Henley.

Funtowicz, S. O. and Ravetz, J. R.: 1990, Uncertainty and Quality in Science for Policy, Kluwer Academic Publishers, Dordrecht, The Netherlands.

Groenenberg, H.: 2002, Development and Convergence. A Bottom-Up Analysis for the Differentiation of Commitments under the Climate Convention. Thesis. Utrecht University, Utrecht, The Netherlands.

Groenenberg, H., Blok, K., and van der Sluijs, J. P.: 2005, 'Global Triptych: A bottom-up approach for the differentiation of commitments under the Climate Convention', Climate Policy 4, 153-175. 
Groenenberg, H., Phylipsen, D., and Blok, K.: 2001: 'Differentiating commitments world wide: Global differentiation of GHG emissions reductions based on the Triptych approach - A preliminary assessment', Energy Policy 29, 1007-1030.

Gupta, J.: 1999, 'North-South aspects of the climate change issue: Towards a constructive negotiating package for developing countries', Reciel 8, 198-208.

Gupta, J., van der Werff, P., Gagnon-Lebrun, F., and van Dijk, I.: 2001, Bridging Interest, Classification and Technology Gaps in the Climate Change Regime, IVAM Environmental Research UvA BV and Institute of Environmental Sciences, Free University, Amsterdam.

Houghton, J. T., Meira Filho, L. G., Lim, B., Treanton, K., Mamaty, I., Bonduki, B., Griggs, D. J., and Callender, B. A. (eds.): 1996, Revised 1996 IPCC Guidelines for National Greenhouse Gas Inventories, UK Meteorological Office, Bracknell, United Kingdom.

IEA: 1997a, $\mathrm{CO}_{2}$ Emissions from Fuel Combustion 1972-1995, International Energy Agency, Paris.

IEA: 1997b, Energy Statistics and Balances of Non-OECD Countries 1971-1995, International Energy Agency, Paris.

IEA: 1998, Electricity Information 1997, International Energy Agency, Paris.

IMAGE team: 2001, The IMAGE 2.2 implementation of the SRES scenarios: A Comprehensive Analysis of Emissions, Climate Change and Impacts in the 21 st Century, National Institute for Public Health and the Environment, Bilthoven, The Netherlands.

Keilman, N.: 1997, 'Ex-post errors in official population forecasts in industrialized countries', $J$. Official Statistics 13, 245-277.

Lutz, W.: 1996, The Future Population of the World: What Can We Assume Today? 2nd edition, Earthscan, London.

Meyer, A.: 2000, Contraction \& Convergence. The Global Solution to Climate Change, Green Books, Bristol, United Kingdom.

Morgan, M. G. and Henrion, M.: 1990, Uncertainty, a Guide to Dealing with Uncertainty in Quantitative Risk and Policy Analysis, Cambridge University Press, Cambridge.

Müller, B.: 2001, 'Varieties of distributive justice in climate change', Climatic Change 48, 273288.

Nakićenović, N. et al. (eds.): 2000, Special Report on Emissions Scenarios, Cambridge University Press, Cambridge.

Olivier, J. G. J., Bouwman, A. F., van der Maas, C. W. M., Berdowski, J. J. M., Veldt, C., Bloos, J. P. J., Visschedijk, A. J. H., Zandveld, P. Y. J., and Haverlag, J. L.: 1996, Description of EDGAR Version 2.0: A set of global emission inventories of greenhouse gases and ozone-depleting substances for all anthropogenic and most natural sources on a per country bases on $1^{\circ} \times 1^{\circ}$ grid, National Institute of Public Health and the Environment, Bilthoven, The Netherlands.

Philibert, C.: 2001a, 'Evolution of mitigation commitments: Certainly versus stringency', International Energy Agency, Vienna.

Philibert, C.: 2001b, 'Evolution of mitigation commitments: Fixed targets versus more flexible architectures', International Energy Agency, Vienna.

Philibert, C. and Pershing, J.: 2001, 'Considering the options: Climate targets for all countries', Climate Policy 1, 211-227.

Phylipsen, G. J. M., Bode, J. W., Blok, K., Merkus, H., and Metz, B.: 1998, 'A Triptych sectoral approach to burden differentiation; GHG emissions in the European bubble', Energy Policy 26, 929-943.

Ravetz, J. R.: 2001, 'Models of risks: An exploration', in Dunn W. N., Hisschemoller, M., Hoppe, R., and Ravetz, J. R. (eds.), Knowledge, Power, and Participation in Environmental Policy Analysis, Special Issue Policy Studies Review Annual, pp. 471-492.

Ringius, L.: 1999, 'Differentiation, leaders, and fairness: Negotiating climate commitments in the European Community', International Negotiations 4, 133-166. 
Ringius, L., Torvanger, A., and Underdal, A.: 2000, Burden Differentiation: fairness Principles and Proposals: The Joint CICERO-ECN Project on Sharing the Burden of Greenhouse Gas Reduction Among Countries, Energy research Centre of the Netherlands, Petten and Centre for International Climate and Environmental Research - Oslo.

Ringius, L., Torvanger, A., and Underdal, A.: 2002, 'Burden sharing and fairness principles in international climate policy', International Environmental Agreements: Politics, Law and Economics 2, 1-22.

Risbey, J., Van der Sluijs, J. P., and Ravetz, J.: 2001, A protocol for assessment of uncertainty and strength of emissions data, Department of Science, Technology and Society, Utrecht University, Utrecht, The Netherlands.

Rose, A.: 1992, 'Equity considerations of tradeable carbon emission entitlements', in Combating Global Warming. Study on a Global System of Tradeable Carbon Emission Entitlements, United Nations Conference on Trade and Development, New York.

Rotmans, J. and de Vries, B. (eds.): 1997, Perspsectives on Global Change: The TARGETS Approach, Cambridge University Press, Cambridge.

Schwarz, M. and Thompson, M.: 1990, Divided We Stand. Redefining Politics, Technology and Social Choice, Harvester Wheatsheaf, New York.

Sijm, J., Jansen, J., and Torvanger, A.: 2001, 'Differentiation of mitigation commitments: The multiSector convergence approach', Climate Policy 1, 481-497.

Sjöberg, L.: 1997, 'Explaining risk perception: An empirical evaluation of cultural theory', Risk Decision and Policy 2, 113-130.

Van der Sluijs, J. and Kloprogge, P.: 2001, 'The inclusion of stakeholder perspectives in integrated assessment of climate change,' in Decker, J. (ed.), Interdisciplinarity in technoogy assessment. Implementations and their chances and limits. Series: "Wissenschaftsethik un technikfolgenbeurteiling”, Vol. 11, pp. 199-214, Springer, Berlin Heidelberg, New York.

Van der Sluijs, J. P.: 2001, 'Integrated assessment models and the participatory challenge. The case of climate change', in Dunn W. N., Hisschemoller, M., Hoppe, R., and Ravetz, J. R. (eds.), Knowledge, Power, and Participation in Environmental Policy Analysis, special issue Policy Studies Review Annual, pp. 317-348.

Van der Sluijs, J. P., Hisschemoller, M., de Boer, J., and Kloprogge, P.: 2002, 'Climate risk assessment, evaluation of approaches', Summary and synthesis report. NRP report, Utrecht University.

Stirling, A. and Mayer, S.: 2001, 'A novel approach to the appraisal of technological risk: A multicriteria mapping study of a genetically modified crop', Environment and Planning C: Government and Policy 19, 529-555.

Thompson, M., Ellis, R., and Wildavsky, A.: 1990, Cultural Theory, Westview Press, Boulder, San Francisco and Oxford.

Trisoglio, A.: 1995, Plurality and Political Culture: A Response to Thompson and Drake, paper presented at workshop "Risk, Policy and Complexity", 7-9 August 1995, IIASA, Laxenburg.

Turkenburg, W. C. and van der Sluijs, J. P.: 2000, Review van het RIVM instrumentarium voor de totstandkoming van lange termijn prognoses met betrekking tot de emissies van broeikasgassen, Department of Science, Technology and Society, Utrecht, The Netherlands.

UN: 1998, World Population Projections to 2150, United Nations Department of Economic and Social Affairs Populations Division, New York.

WEC: 1995, Energy Efficiency Improvement Utilising High Technology. An Assessment of Energy Use in Industry and Buildings, World Energy Council, London.

(Received 8 April 2002; in revised form 2 July 2004) 